\title{
Activation of MAPK overrides the termination of myelin growth and replaces Nrg1/ErbB3 signals during Schwann cell development and myelination
}

\author{
Maria E. Sheean, ${ }^{1,9}$ Erik McShane, ${ }^{2,9}$ Cyril Cheret, ${ }^{1,9}$ Jan Walcher, ${ }^{3}$ Thomas Müller, ${ }^{1}$ \\ Annika Wulf-Goldenberg, ${ }^{4}$ Soraya Hoelper, ${ }^{5}$ Alistair N. Garratt, ${ }^{1,10}$ Markus Krüger, ${ }^{5}$ Klaus Rajewsky, ${ }^{6}$ \\ Dies Meijer, ${ }^{7}$ Walter Birchmeier, ${ }^{8}$ Gary R. Lewin, ${ }^{3}$ Matthias Selbach, ${ }^{2,11}$ and Carmen Birchmeier ${ }^{1,11}{ }^{1}$ \\ ${ }^{1}$ Developmental Biology/Signal Transduction, ${ }^{2}$ Cell Signaling/Mass Spectrometry, ${ }^{3}$ Molecular Physiology of Somatic Sensation, \\ Max Delbrueck Center for Molecular Medicine, 13125 Berlin, Germany; ${ }^{4}$ Experimental Pharmacology and Oncology Berlin-Buch \\ $\mathrm{GmbH}, 13125$ Berlin-Buch, Germany; ${ }^{5}$ Max-Planck-Institute for Heart and Lung Research, 61231 Bad Nauheim, Germany; \\ ${ }^{6}$ Immune Regulation and Cancer, Max Delbrueck Center for Molecular Medicine, 13125 Berlin, Germany; ${ }^{7}$ Department of Cell \\ Biology and Genetics, Erasmus University Medical Center, 3000 DR Rotterdam, Netherlands; ${ }^{8}$ Signal Transduction, Invasion, \\ and Metastasis, Max Delbrueck Center for Molecular Medicine, 13125 Berlin, Germany
}

Myelination depends on the synthesis of large amounts of myelin transcripts and proteins and is controlled by Nrg1/ErbB/Shp2 signaling. We developed a novel pulse labeling strategy based on stable isotope labeling with amino acids in cell culture (SILAC) to measure the dynamics of myelin protein production in mice. We found that protein synthesis is dampened in the maturing postnatal peripheral nervous system, and myelination then slows down. Remarkably, sustained activation of MAPK signaling by expression of the Mek1DD allele in mice overcomes the signals that end myelination, resulting in continuous myelin growth. MAPK activation leads to minor changes in transcript levels but massively up-regulates protein production. Pharmacological interference in vivo demonstrates that the effects of activated MAPK signaling on translation are mediated by mTORindependent mechanisms but in part also by mTOR-dependent mechanisms. Previous work demonstrated that loss of ErbB3/Shp2 signaling impairs Schwann cell development and disrupts the myelination program. We found that activated MAPK signaling strikingly compensates for the absence of ErbB3 or Shp2 during Schwann cell development and myelination.

[Keywords: myelin; translational control; MAPK; pSILAC]

Supplemental material is available for this article.

Received September 4, 2013; revised version accepted December 20, 2013.

Myelination of axons is essential for the function of the nervous system, and deficits in myelination cause devastating disease (Suter and Scherer 2003; Quarles et al. 2006). Myelin sheaths electrically insulate axonal membranes and allow fast propagation of nerve impulses by saltatory conduction (Huxley and Stampfli 1949). The thickness of myelin sheaths is believed to be optimized for maximal conduction velocity (Smith and Koles 1970; Waxman 1980). In the peripheral nervous system, Schwann

\footnotetext{
${ }^{9}$ These authors contributed equally to this work.

${ }^{10}$ Present address: Institute of Cell Biology and Neurobiology, CharitéUniversitätsmedizin Berlin, 10117 Berlin, Germany.

${ }_{11}$ Corresponding authors

E-mail cbirch@mdc-berlin.de

E-mail matthias.selbach@mdc-berlin.de

Article is online at http://www.genesdev.org/cgi/doi/10.1101/gad.230045.113. Freely available online through the Genes \& Development Open Access option.
}

cells generate the myelin sheath. Only medium- and largecaliber axons are myelinated, and myelin sheath thickness is proportional to the axonal diameter (Donaldson and Hoke 1905). Myelination is therefore closely controlled and is accompanied by the production of large amounts of myelin transcripts and proteins by the ensheathing glia. The transcriptional control of myelination has been intensely studied (Svaren and Meijer 2008), but due to technical limitations, less is known about the translational control.

Post-transcriptional mechanisms play central roles in gene expression. In fibroblasts, only $\sim 40 \%$ of the variability

(C) 2014 Sheean et al. This article, published in Genes \& Development, is available under a Creative Commons License (Attribution-NonCommercial 3.0 Unported), as described at http://creativecommons.org/licenses/ by-nc/3.0/. 
in protein levels can be attributed to mRNA levels (Schwanhäusser et al. 2011). Quantitative proteomic analysis can be achieved by mass spectroscopy using stable (i.e., nonradioactive) isotope labeling with amino acids in cell culture (SILAC) and in mice (Krüger et al. 2008; Cox and Mann 2011). In cultured cells, pulsed SILAC (pSILAC) and dynamic SILAC techniques have been used to quantify protein synthesis and degradation (Selbach et al. 2008; Doherty et al. 2009; Schwanhäusser et al. 2011). Initiation of protein translation is highly regulated and rate-limiting in protein biosynthesis. Recognition of the 5' mRNA cap structure and ribosomal recruitment are critical in this regulation (Ma et al. 2005; Kong and Lasko 2012). Cap recognition and ribosome recruitment are accomplished by eukaryotic initiation factor 4E (eIF4E) and eIF4E-binding proteins (4EBPs). Growth factor signaling-dependent phosphorylation of 4EBPs and eIF4E enhance initiation of translation (Kong and Lasko 2012). The mTOR complex 1 (mTORC1) phosphorylates two key proteins in translational control: 4EBP1 and p70 S6 kinase (Hay and Sonenberg 2004; Dowling et al. 2010; Song et al. 2012). In addition, MAPK signaling also stimulates protein production, as demonstrated in neurons and cancer cells (Kelleher et al. 2004; Topisirovic and Sonenberg 2011). MAPK signaling activates Mnk1 and p90 ribosome S6 kinases (Rsk1-3) (see Pyronnet et al. 1999; Roux et al. 2007). MAPK signaling also phosphorylates the negative regulator of mTORC1 (Tsc2) and thus increases mTORC1 activity (Ma et al. 2005). Little is known about the control of protein translation during myelination.

In mice, myelination of peripheral nerves begins around birth and continues into adulthood (Sherman et al. 2012). Myelination is regulated by tyrosine kinase receptors, integrins, and G-protein-coupled receptors and involves complex changes in cell morphology and the generation of large amounts of myelin (Nodari et al. 2007; Newbern and Birchmeier 2010; Monk et al. 2011). Notably, Neuregulin-1 (Nrg1) provides an important neuronal signal that activates ErbB2 and ErbB3 tyrosine kinase receptors and controls Schwann cell development and myelination (Riethmacher et al. 1997; Garratt et al. 2000; Michailov et al. 2004; Lyons et al. 2005; Taveggia et al. 2005). Nrg1 signaling influences the transcriptional myelination program at the onset of myelination, during the myelination process, and in myelin repair (Murphy et al. 1996; Lyons et al. 2005; Taveggia et al. 2005; Fricker et al. 2013). Shp2/ MAPK, PI3K/Akt, PLC, and Rac1 signaling is activated by Nrg1 and was implicated in myelination by genetic analyses in mice (for review, see Newbern and Birchmeier 2010). In particular, mutation of the MAP kinases Erk1 and Erk2 or dampening of MAPK signaling after ablation of the cytoplasmic tyrosine phosphatase Shp2 severely disrupts Schwann cell development and myelination, causing phenotypes similar to those observed in $\mathrm{Nrg} 1$ or ErbB2 mutants (Grossmann et al. 2009; Newbern et al. 2011). mTOR mutation retards radial and longitudinal growth of Schwann cells and results in the formation of thin myelin accompanied by reduced phosphorylation of the mTOR substrates S6 and 4EBP1 (Sherman et al. 2012).
Myelination ceases in the maturing peripheral nervous system, which was proposed to be controlled by a Dlg1mediated down-regulation of PI3K/Akt signaling in Schwann cells (Cotter et al. 2010).

MAP kinase kinase 1 (Mek1) activates MAPK signaling by phosphorylating Erk1 and Erk2. Here we report that mild but sustained activation of MAPK signaling in Schwann cells by Mek1DD (a signaling-on allele) suffices to replace ErbB3 and Shp2 during Schwann cell development and myelination. Furthermore, sustained MAPK signaling induced by Mek1DD results in continuous myelin growth. We developed a novel in vivo pulse labeling technique based on SILAC to directly quantify protein production, which allowed us to assess translational changes during myelination. Our data demonstrate that sustained MAPK signaling enhances protein production and thus overcomes the attenuated translation that accompanies the maturation of the peripheral nervous system.

\section{Results}

Protein translation is markedly down-regulated during maturation of peripheral nerves

Normal development of the peripheral nervous system is characterized by rapid myelin growth in the postnatal period, which then slows during maturation. In particular, radial myelin growth is fast during the first two postnatal weeks in mice, reflected by a decrease in g-ratio (axon diameter/myelinated fiber diameter) that reaches a plateau around postnatal day 15 (P15). Subsequently, myelin continues to grow at slower rates: first, radially, mostly due to increasing axon diameter, and second, longitudinally, due to an increase of animal size and nerve length (see Fig. 1A for illustration; cf. Court et al. 2004; Sherman et al. 2012). We observed that maturation is accompanied by a marked reduction of phosphorylated Erk1/2 (p-Erk1/2) and p-Akt and a reduction of overall levels of Erk1/2, Akt, and ErbB3 in peripheral nerves (Fig. 1B). We also noted that various proteins known to control protein translation, like eIF4E and S6, were down-regulated in level and phosphorylation status during maturation (Fig. 1B).

We therefore determined protein production during maturation of peripheral nerves in an unbiased manner. Recently developed pulsed metabolic labeling methods can be used to measure protein synthesis and decay in cultured cells (Selbach et al. 2008; Doherty et al. 2009). This strategy was adapted to quantify changes in protein synthesis in vivo (Fig. 1C). P30 mice were pulse-labeled for $1 \mathrm{wk}$ by feeding them chow containing heavy lysine (Lys8). Since pulse labeling with solid diet is not possible before weaning, we pulse-labeled P8 pups for $1 \mathrm{wk}$ with Lys6-labeled milk by providing Lys6-labeled foster mothers. Ratios of heavy-labeled (Lys8 or Lys6) to lightlabeled (Lys0) peptides were measured separately in samples prepared from sciatic nerves of young and old mice. To allow a direct comparison and take into account differences in size and protein content of "old" and "young" nerves, additional "spike-in" experiments were performed 
Sheean et al.

A

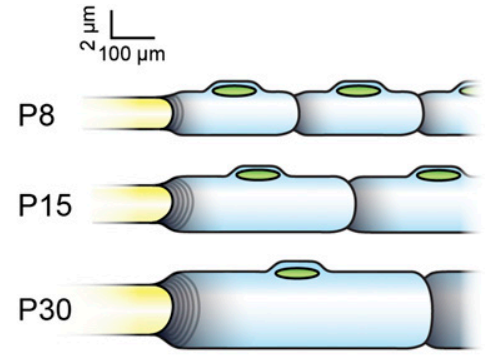

B

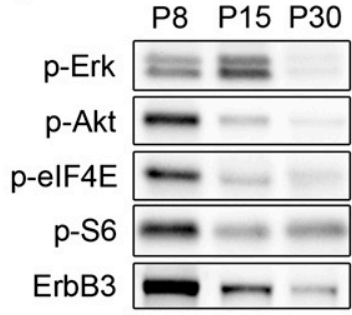

P8 P15 P30

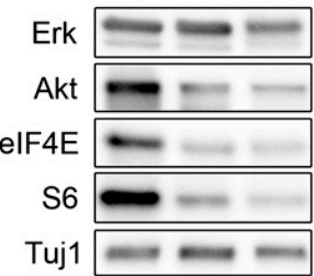

C pulse SILAC labeling of adults:

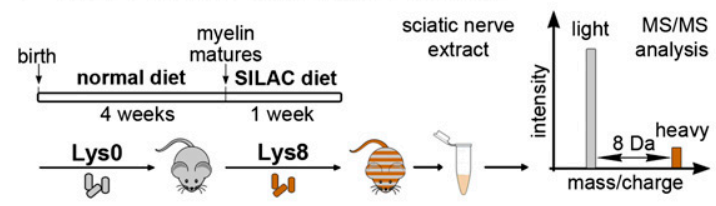

pulse SILAC labeling of young pups:
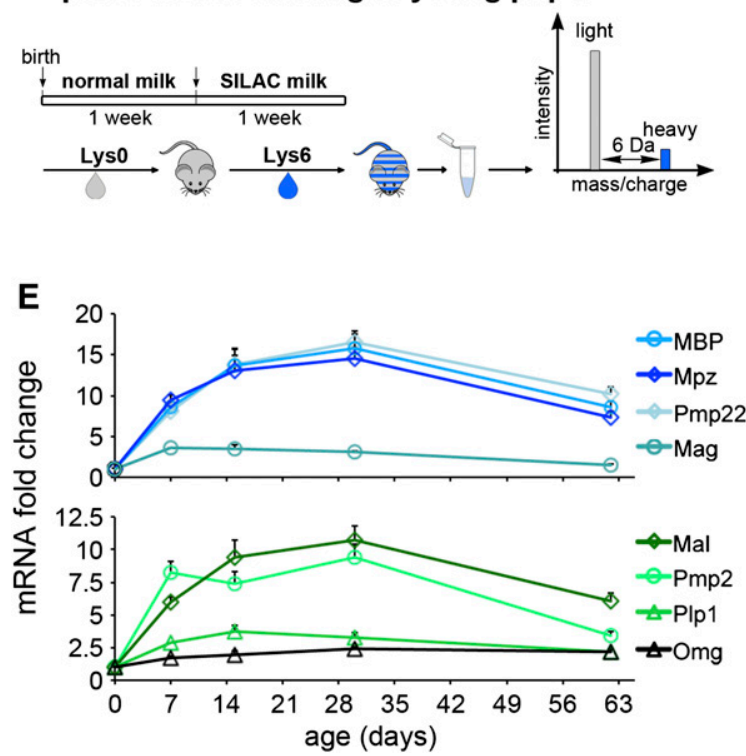

D de novo protein synthesis

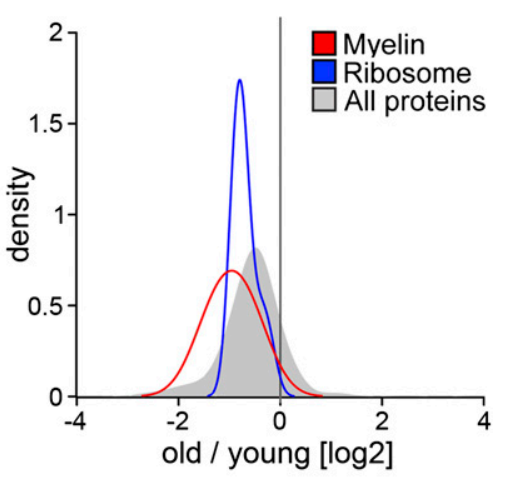

$F$

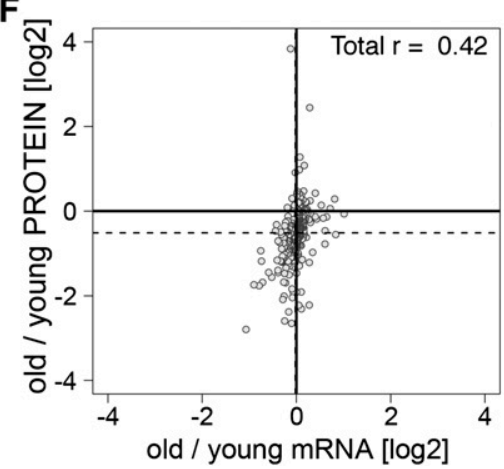

Figure 1. Protein synthesis and Nrg1 signaling are down-regulated in maturing nerves. (A) Growth of myelinating Schwann cells at P8, $\mathrm{P} 15$, and P30 is shown schematically. Axon diameter, myelin thickness, and internodal distance are scaled to display average changes (cf. Court et al. 2004). (B) Western blot analysis investigating phosphorylation of signaling molecules in sciatic nerves of P8, P15, and P30 mice. Tuj1 was used as loading control. (C) Outline of the pSILAC experiment performed to estimate protein synthesis in nerves of "old" and "young" mice. SILAC labeling was achieved by feeding Lys8-labeled chow or providing Lys6-labeled animals as foster mothers. (D) Kernel density estimation plots showing the fold change of newly synthesized proteins in the nerves of mice at P30 (old) versus P8 (young) as assessed by pSILAC and mass spectrometry; overall proteins or selected protein groups (ribosome, myelin) (cf. Supplemental Table 1) are displayed. A shift to the left indicates decreased protein production in old mice. (E) qPCR analysis of myelin gene expression from P0 to P62, normalized to an external control RNA from Caenorhabditis elegans (eif-3.D) and plotted as fold change of the expression observed at P0. Error bars indicate SEM. (F) Correlation plot, comparison of fold changes in protein production, and mRNA levels between old and young animals. Protein synthesis was assessed comparing P8 and P30 mice pulse-labeled for 1 wk. RNA expression was compared between P11 and P33 by microarray analysis, normalized to ERCC RNA spike-in. We observed poor correlation between changes in protein synthesis and steady-state mRNA levels.

(see the Material and Methods). We observed a general down-regulation of de novo production of overall protein and particularly ribosomal and myelin proteins in the "old" nerves (Fig. 1D; Supplemental Table 1).

We next examined whether changes in myelin mRNA levels can account for or contribute to the down-regulated myelin production. Numbers of myelinating Schwann cells in the sciatic nerves change little between P7 and P42 (Court et al. 2004), but the length and diameter of axons increase. To allow a direct comparison of mRNA levels, we isolated entire nerves and used RNA spike-in for normalization (cf. the Material and Methods and 
Loven et al. 2012). Quantitative PCR (qPCR) analyses demonstrated that the expression of most myelin mRNAs peaked around P30; i.e., were higher at P30 than at P8 (Fig. 1E). Thus, at the time when myelin mRNA levels peaked, myelin protein synthesis was already down-regulated. To compare changes in protein production and mRNA levels in old and young nerves, we performed microarray expression analyses again using spike-in for normalization (Supplemental Material; Supplemental Table 2). Changes in protein production and transcript levels correlated poorly when young and old nerves were compared (Pearson's correlation coefficient of +0.42 ) (Fig. 1F). Thus, our data indicate that protein synthesis is down-regulated during maturation of the peripheral nervous system. In particular, myelin protein synthesis is reduced prior to the decrease in the expression of the corresponding mRNAs.

\section{Activation of Mek1 results in continuous myelin growth}

Activation of MAPK and PI3K signaling was reported to result in nerve hypermyelination (Narayanan et al. 2009; Ishii et al. 2013). We next tested whether activation of these signaling systems overcomes the signals that end myelination. We expressed a gain-of-function Mek1 variant $(M e k 1 D D)$ in murine Schwann cells in vivo using a Mek1DD transgene expressed upon $\mathrm{Egr2}^{\mathrm{Cre}}$-mediated deletion of a translational stop cassette $\left(E g r 2^{\mathrm{Cre}} ; \mathrm{Mek} 1 \mathrm{DD}\right.$ mice are subsequently called Mek1DD mutants) (Supplemental Fig. S1A; cf. Voiculescu et al. 2000; Srinivasan et al. 2009). In such mice, Cre is expressed in myelinating Schwann cells starting around embryonic day 16 (E16). Mek1 phosphorylates and activates Erk1/2, and, in accordance, we observed enhanced Erk $1 / 2$ phosphorylation in peripheral nerves of Mek1DD at P8, P15, and P30 compared with control mice (Fig. 2A). However, Akt phosphorylation was affected little or not affected, although overall Akt protein levels were elevated (Fig. 2A).

We analyzed myelination in Mek1DD mice, which began prematurely with $5.8 \pm 3.1$ and $12.4 \pm 5.8$ myelinated fibers per field at $\mathrm{P} 0$ in control and Mek1DD mice, respectively. Furthermore, myelin sheaths were thicker at P15 or P30, and myelin continued to grow radially until P90, the latest stage at which the strain was analyzed (Fig. 2B; Supplemental Fig. S1B). Thus, the g-ratio failed to
A
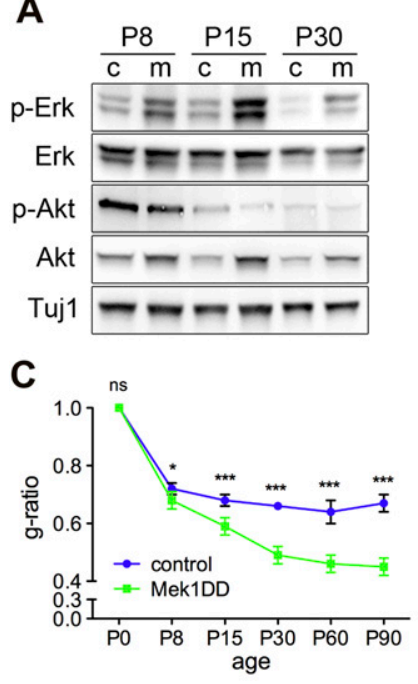

B

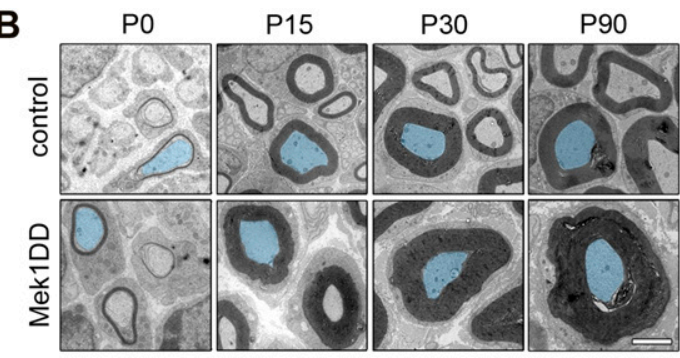

D

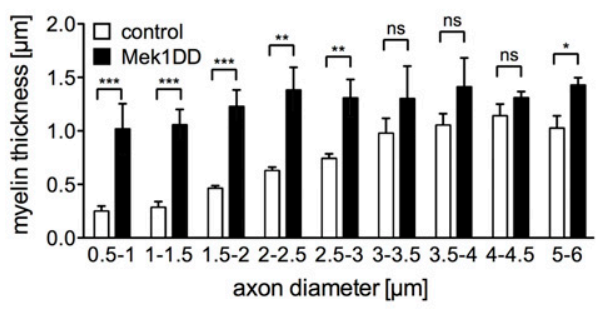

E
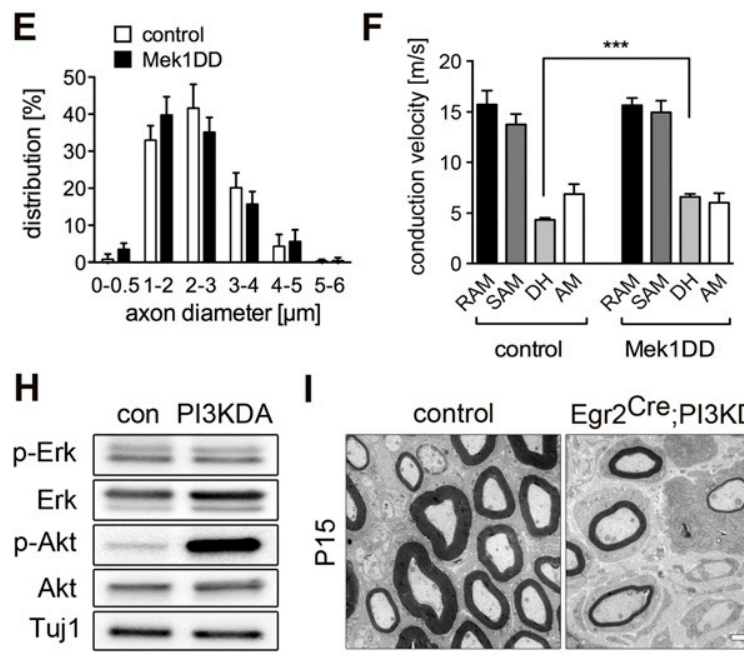

I

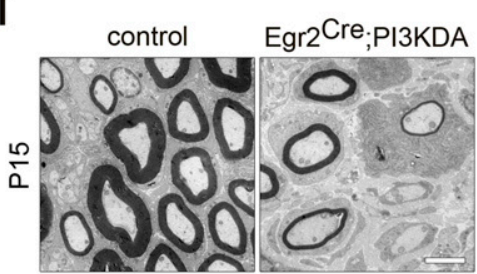

G

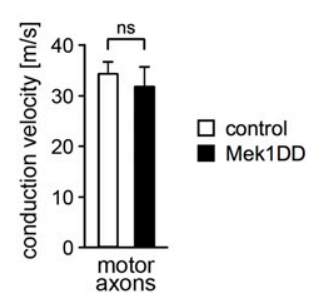

J

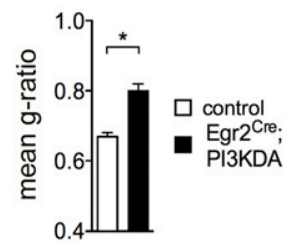

Figure 2. Activation of MAPK signaling results in continuous myelin growth. $(A)$ Western blot analysis of total and phosphorylated Erk1/2 and Akt in sciatic nerves of control (c) and Mek1DD (m) mice at P8, P15, and P30. Neuronal tubulin (Tuj1) was used as loading control. (B) Analysis of nerves from control and Mek1DD mice (P0-P90) by electron microscopy. Representative axons of similar diameters were false-colored. $(C)$ Mean g-ratios of fibers in sciatic nerves of control and Mek1DD mice at the indicated ages. (D) Binning analysis of myelin thickness of groups of axons with the indicated diameters; the nerves of control and Mek1DD mice at P30 were analyzed. (E) Distribution of axon diameters in sciatic nerves of control and Mek1DD mice at P30 $(n=90$ units total, three mice per genotype). (F) Conduction velocities of rapidly adapting mechanoreceptors (RAM), slowly adapting mechanoreceptors (SAM), D-hair mechanoreceptors (DH), and $\mathrm{A} \delta$ mechanonociceptors (AM) in saphenous nerves at P30. $(G)$ Conduction velocities of motoneurons in ventral roots at P30. $(H)$ Western blot analysis of sciatic nerve extracts from control and PI3KDA P15 animals; expression of PI3KDA enhanced Akt but not Erk1/2 phosphorylation. Electron microscopy analysis $(I)$ and quantification of myelin thickness (g-ratio) $(J)$ of control and PI3KDA mice (P15). (C,D,F, $)$ Two-tailed unpaired $t$-test. $(G)$ Two-way ANOVA (129-145 ventral root fibers tested from L4-6, three mice per genotype).

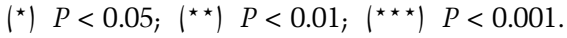
Error bars indicate SD $(C-E, G, I)$ and SEM $(F)$. Bars: $B, I, 2 \mu \mathrm{m}$. 
level off in Mek1DD mutants (Fig. 2C). We estimated that the mean myelin area in peripheral nerves at $\mathrm{P} 90$ was increased sixfold compared with controls. Increased myelin thickness was particularly pronounced in smalldiameter fibers (Fig. 2D), and, rarely, axons with a diameter of $<1 \mu \mathrm{m}$ were myelinated in Mek $1 D D$ nerves. In contrast, control and Mek1DD mice showed no difference in axonal diameters (Fig. 2E), Schwann cell numbers $(358 \pm 22$ and $416 \pm 45$ nuclei per section; $P=0.17)$, internodal distances $(551.8 \pm 87.6$ and $553.4 \pm 81.4 \mu \mathrm{m})$, and the morphology of nodes of Ranvier and paranodes (Supplemental Fig. S1C). Mek1DD expression was also accompanied by a marked increase in the diameter of sciatic nerves due to massive hypermyelination and reduced axonal packing $(0.49 \pm 0.23$ and $0.96 \pm 0.36 \mu \mathrm{m}$; distance between nerve fibers in control and Mek1DD mice, respectively) (Supplemental Fig. S1D,E). We conclude from these data that activation of MAPK signaling perpetuates radial myelin growth and results in a pronounced hypermyelination.

Myelin thickness is a determinant of conduction velocity, but the effect of hypermyelination on conduction velocities was not examined experimentally before. Mechanosensory fibers are myelinated, and, in skin-nerve preparations, physiologically distinct mechanosensory fiber types are distinguishable by firing properties and conduction velocities (Milenkovic et al. 2008). We noted that D-hair mechanoreceptors displayed significantly increased conduction velocity in $M e k 1 D D$ compared with control mice at P30, but conduction velocities of other mechanosensory fibers were unchanged (Fig. 2F). Conduction velocities of myelinated $\alpha$-motoneurons were measured in ventral root/sciatic nerve preparations and were similar in control and Mek1DD mice (Fig. 2G). We also examined the effect of a constitutively active variant of PI3K (PI3KDA) (cf. Srinivasan et al. 2009) on myelination (Supplemental Fig. S1F). PI3KDA expression was initiated by $\mathrm{Egr}^{\mathrm{Cre}}$-mediated recombination and was accompanied by very pronounced enhancement of Akt but not Erk1/2 phosphorylation (Fig. 2H). Expression of PI3KDA strongly interfered with myelination (Fig. 2I,J).

\section{Continuous myelination in Mek1DD mice results in pathological myelin structures}

In addition to continuous myelin growth, we observed in Mek1DD mice a number of myelin abnormalities. For instance, myelin abundance at $\mathrm{P} 60$ compressed the axoplasm of some fibers (asterisks in Fig. 3A), and we observed aberrant paranodal myelin (tomaculi) and infolded myelin loops (Fig. 3A). In addition, "onion bulb" structures were observable (onion bulbs are signs of myelin degeneration and regeneration) (arrowhead in Fig. 3A; cf. Suter and Scherer 2003). Myelin abnormalities were present at P30-P90 but not P15 (quantified in Fig. 3B), indicating that they resulted from massive hypermyelination. Furthermore, analysis of myelin ultrastructure showed that stacking of myelin sheaths in compact myelin was unaffected (space between myelin sheaths: $14.3 \pm 2.7$ and $13.0 \pm 1.7 \mathrm{~nm}$ in control and Mek1DD mice,
A

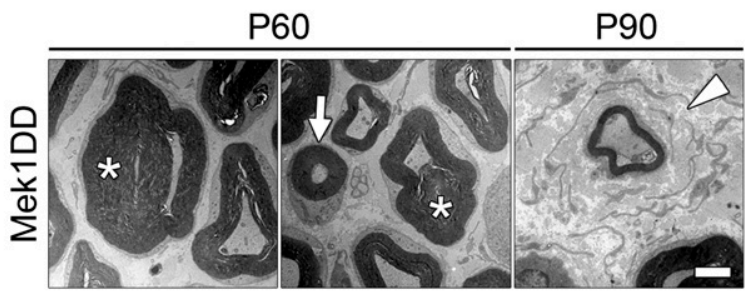

B

\begin{tabular}{|c|c|c|c|c|}
\cline { 2 - 5 } \multicolumn{1}{c|}{} & \multicolumn{4}{c|}{ \% Misfolds \pm SD } \\
\cline { 2 - 5 } \multicolumn{1}{c|}{} & P15 & P30 & P60 & P90 \\
\hline Control & $0.0 \pm 0.0$ & $2.3 \pm 1.4$ & $4.1 \pm 0.9$ & $4.9 \pm 4.1$ \\
\hline Mek1DD & $0.1 \pm 0.0^{\text {ns }}$ & $11.5 \pm 2.0^{* \star *}$ & $24.9 \pm 10.0^{* *}$ & $32.6 \pm 7.4^{* \star}$ \\
\hline
\end{tabular}

C

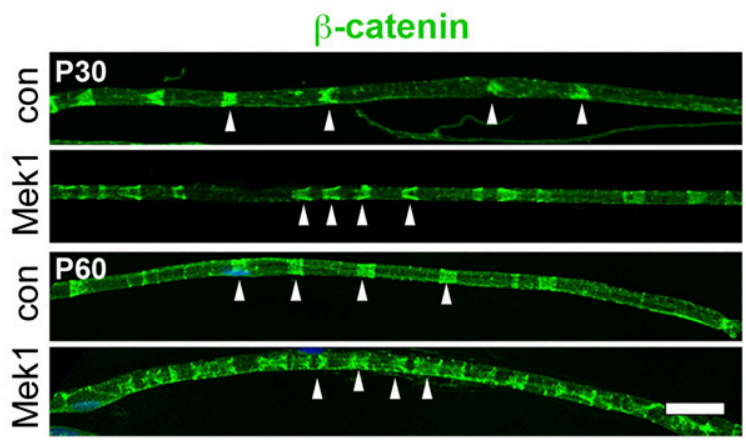

D

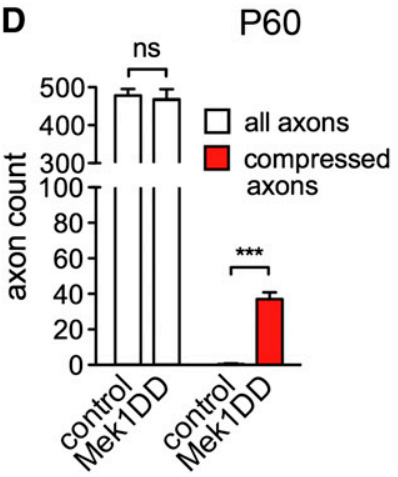

E

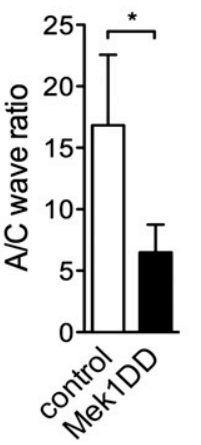

P60

Figure 3. Prolonged activation of MAPK signaling results in the formation of aberrant myelin structures and in physiological deficits. (A) Aberrant myelin structures in sciatic nerves of $M e k 1 D D$ mice at the indicated ages; asterisks indicate compressed axons, the arrow indicates a myelinated axon with $<1 \mu \mathrm{m}$ axonal diameter, and the arrowhead indicates an "onion bulb" structure. $(B)$ Percentage of misfolded myelin structures identified in control and Mek1DD mice at the indicated ages. $(C)$ Visualization of Schmidt-Lanterman incisures using $\beta$-catenin staining of teased nerve fibers. Nerves from Mek1DD (Mek1) and control (con) animals are displayed. (D) Quantification of total axon numbers and axons displaying a severe compression in saphenous nerve. $(E)$ Ratio of $\mathrm{A} / \mathrm{C}$ compound action potential in nerves of control and Mek1DD mice (five to six mice per genotype) (left) and quantification of active units per axon filament detected in conduction velocity tests (right). Bars, $A$, $2 \mu \mathrm{m} ; C, 50 \mu \mathrm{m}$. (B,D,E, left) Two-tailed unpaired $t$-test. (E, right) Mann-Whitney $U$-test. $\left.\left({ }^{\star}\right) P<0.05 ;\left({ }^{\star \star}\right) P<0.01 ;{ }^{\star * \star}\right) P<0.001$. Error bars indicate SEM. 
respectively|, but noncompact myelin structures were more abundant (Schmidt-Lanterman incisures, indicated by arrowheads in Fig. 3C).

The abnormal myelin structures observed at the late stages in Mek1DD mice profoundly affected nerve physiology. Conduction velocities in D-hair mechanoreceptors of Mek1DD mice were enhanced at P30, but such differences were no longer observable after P60 (Supplemental Fig. S2A). Although it became difficult to find mechanoreceptive fibers in the saphenous nerve of Mek1DD mice after P60, myelinated axon numbers and mechanoreceptive skin innervation appeared unaffected (Fig. 3D; Supplemental Fig. S2B). The occurrence of compressed axons (Fig. 3A,D) might result in a conduction block. We therefore determined the ratio of compound action potentials in myelinated $\mathrm{A}$ and nonmyelinated $\mathrm{C}$ fibers (A/C fiber waves) and quantified numbers of active mechanoreceptive units. A reduced ratio of $\mathrm{A} / \mathrm{C}$ fiber waves and reduced numbers of active mechanoreceptive units were observed in Mek1DD mice after P60 (Fig. 3E), indicating that many myelinated axons were not conducting. Thus, the mild hypermyelination in young Mek1DD mice results in increased conduction velocities of D-hair mechanoreceptors, whereas pronounced hypermyelination and myelin abnormalities present at later stages can block conduction.

Mek1DD expression enhances myelin protein production but impinges little on myelin mRNA levels

We next determined the effect of $M e k 1 D D$ on protein production using pSILAC in vivo. Mek1DD and control mice at P30 were pulse-labeled for $1 \mathrm{wk}$ by feeding chow containing medium-heavy lysine (Lys4) and heavy lysine (Lys8), respectively. Subsequently, sciatic nerves were combined and analyzed by mass spectrometry. The ratio of Lys4 to Lys8 peak intensities in mass spectra reflects differences in protein production in vivo (Supplemental Fig. S3; see also the Supplemental Material). We indeed observed higher amounts of labeled proteins in nerves of Mek1DD mice than of control mice (Fig. 4A; see also Supplemental Table 1). The production of ribosomal proteins displayed a particularly strong increase, but myelin proteins and enzymes involved in lipid biosynthesis were also up-regulated. The increase in newly generated proteins might be caused by increased synthesis or decreased degradation. To estimate degradation, we performed a SILAC chase experiment and observed that overall degradation rates were not decreased but actually increased in Mek1DD compared with control nerves (Supplemental Fig. S4A-C). Consistently, proteasome components were also overproduced (Supplemental Fig. S4D). Thus, protein synthesis was strongly increased in nerves of Mek1DD mice, providing a molecular mechanism for the observed hypermyelination.

Next, we compared protein production at an earlier stage, when myelination is actively ongoing in normal development. We pulse-labeled Mek1DD and control pups at P8 with Lys6-labeled milk for $1 \mathrm{wk}$ by providing Lys6-labeled mice as foster mothers. The ratios of Lys6- labeled to Lys0-labeled peptides were measured separately in samples from Mek1DD and control mice, using additional "spike-in" experiments for quantification (cf. the Supplemental Material). Again, newly synthesized proteins were more abundant in Mek1DD compared with control mice (Fig. 4B; see Supplemental Table 1).

We confirmed increased protein production by analyzing steady-state protein levels at P30 using Western blotting. Proteins whose production was strongly increased were indeed present in higher quantities in nerves of Mek1DD mutant mice (Fig. 4C), among them myelin proteins (Pmp2 and Mag) and enzymes controlling lipid biosynthesis (Slc27a4, Fasn, Acly, and Elov17). MBP and $\mathrm{Mpz}$, the major components of peripheral myelin, displayed a 1.8-fold and 1.3-fold increase in steady-state levels, respectively (Fig. 4C). We conclude that MAPK activation in Schwann cells overcomes mechanisms that end myelination by stimulating protein synthesis.

We also compared mRNA levels in control and Mek1DD sciatic nerves using microarray analysis at P8 and P30. Changes in protein production and transcript levels correlated poorly when control and mutant nerves were compared (Fig. 4D,E). In particular, when all transcripts were analyzed, Pearson's correlation coefficients of $r=+0.29$ and -0.28 were found for $\mathrm{P} 30$ and P8, respectively. When only transcripts whose expression changed by $>1.2$-fold were included, the correlation improved at P30 $(r=+0.51)$ but not P8 $(r=-0.34)$. Among the deregulated genes, none encodes transcription factors known to control myelination, and only few encode myelin proteins (see Supplemental Tables 3-5). We reasoned that high mRNA levels of myelin proteins might lead to probe saturation in microarrays and thus to an underestimation of changes in mRNA. Analysis of mRNA expression by qPCR demonstrated that transcript levels of major components of peripheral myelin (e.g., Mpz and MBP) were unaffected at P8, P15, or P30 (Fig. 4F). The only significantly up-regulated myelin mRNA encodes Pmp2, a member of the fatty acid-binding protein family that represents a minor component of peripheral myelin with no known function. Furthermore, five and eight genes encoding enzymes in lipid biosynthesis were up-regulated and down-regulated in microarray experiments, respectively (Supplemental Table 3), and deregulated expression of a subset was verified by qPCR (Supplemental Fig. S5). Among highly up-regulated myelin proteins and lipid biosynthesis enzymes, only Pmp2 and Elov17 displayed a corresponding up-regulation in mRNA levels (Fig. 4C,F; Supplemental Table 3; Supplemental Fig. S5). In summary, enhanced MAPK signaling does not broadly up-regulate the myelination program on a transcriptional level but generally increases protein production.

\section{Mek1DD signals via mTORC1-independent and mTORC1-dependent mechanisms}

MAPK signaling enhances protein translation in cultured cells by activation of Mnk1/2, p90RSK1-3, and mTORC1, which in turn phosphorylate eIF4E, S6, and 4EBP1 (Topisirovic and Sonenberg 2011). We therefore assessed 
Sheean et al.

A
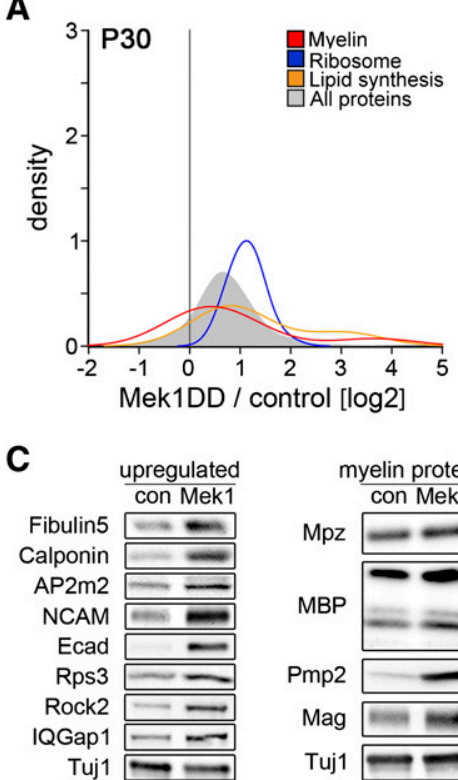

D

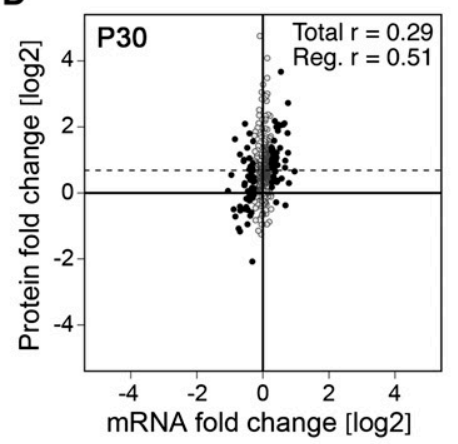

B
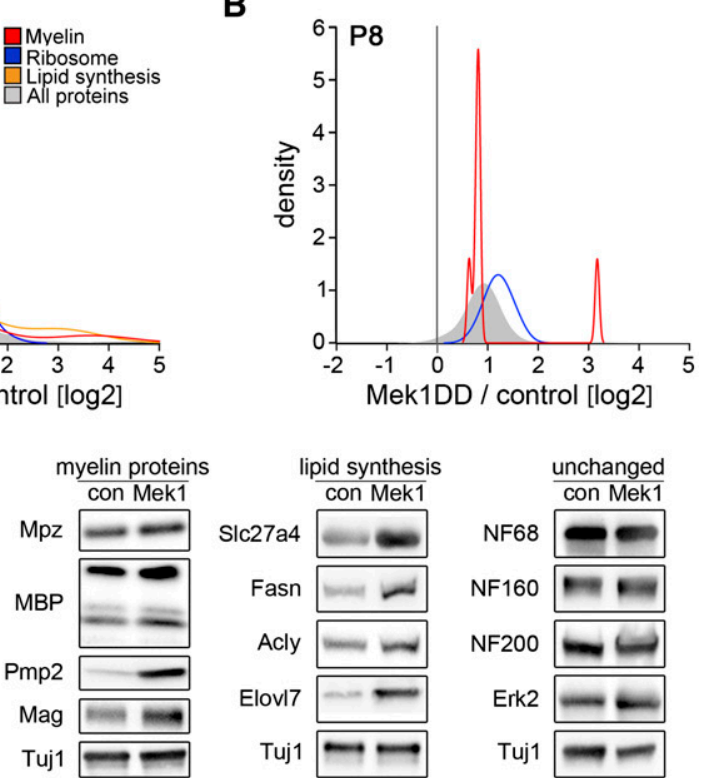

E

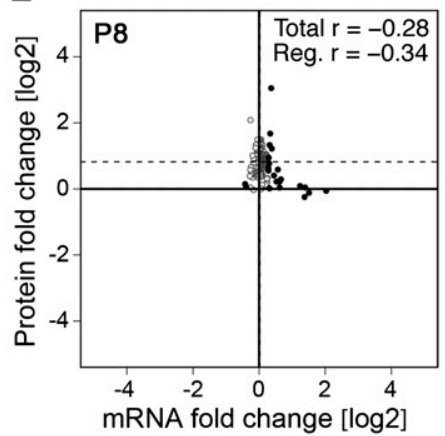

Figure 4. SILAC pulse labeling reveals increased protein synthesis in the nerves of Mek1DD mice. $(A, B)$ Kernel density estimation plots showing the ratios of newly synthesized proteins in $\mathrm{Egr}^{\mathrm{Cre}}$; Mek1DD versus control mice; overall proteins or selected protein groups (ribosome, myelin, and lipid synthesis enzymes) are displayed. The shift to the right indicates an increased protein production in Mek1DD mutants. Enzymes involved in lipid synthesis were not detected when pups were analyzed. $(C)$ Western blot analysis of selected proteins previously detected and quantified in SILAC pulse labeling experiments. Tuj1 was used as loading control. $(D, E)$ Correlation plot comparison of fold changes in protein production and mRNA levels in Mek1DD mutant versus control nerves at P30 and P8; black dots indicate mRNAs that are changed $>1.2$-fold, and dashed lines indicate the average change in protein/mRNA levels. $(F)$ Quantification of transcripts of genes encoding myelin proteins in $\mathrm{P} 8, \mathrm{P} 15$, and $\mathrm{P} 30$ sciatic nerves by qPCR. Two-tailed paired $t$-test: $\left(^{\star}\right) P<0.05 ;\left(^{\star \star}\right) P<$ 0.01. Error bars indicate SD.

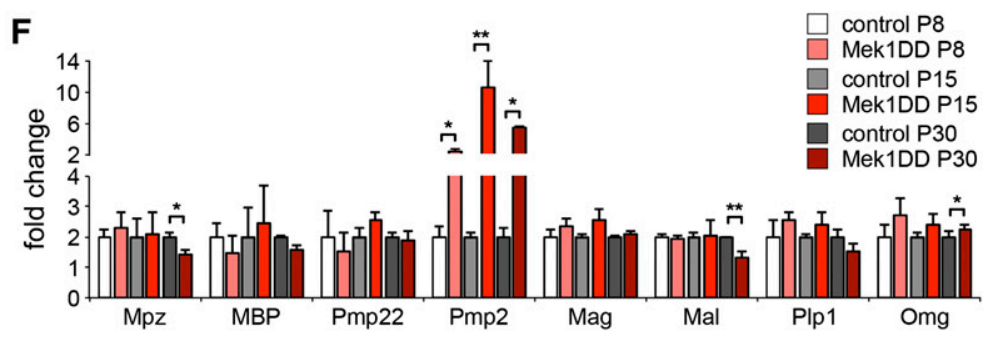

p-S6 levels by immunohistochemistry in Schwann cells on teased nerve fibers from Mek1DD mice and found a pronounced increase (Fig. 5A). Western blotting shows that phosphorylation of eIF4E, S6, 4EBP1, and mTOR were indeed strongly enhanced (Fig. 5B), and overall levels of these proteins were also increased. Regulators of Akt activity (i.e., Dlg1, PTEN, and p-PTEN) were unchanged, and p-Akt levels were also unaffected, but overall Akt protein was increased (Fig. 5B). The increased phosphorylation of eIF4E, S6, 4EBP1, and mTOR suggests mechanisms for the increased protein production.

We next treated Mek1DD mutant mice with the mTORC1 inhibitor everolimus (Schuurman et al. 1997) to test to what extent mTORC1 affects continuous myelin growth. Everolimus treatment started at P17 and extended to P30. Thus, the inhibitor was provided during a period in which overall g-ratios did not change in control mice, whereas myelin growth continued in Mek1DD mutants (see Fig. 2C). Everolimus did not affect myelin thickness in control mice but dampened myelin growth in the nerves of Mek1DD mutants (Fig. 5C,D) and completely rescued the decreased axonal packing in Mek1DD mutants (Fig. 5C,E). The eIF4E protein is a substrate of Mnk1, which is directly activated by MAPK signaling (Waskiewicz et al. 1997). eIF4E phosphorylation was not affected by everolimus, but phosphorylation of mTOR and 


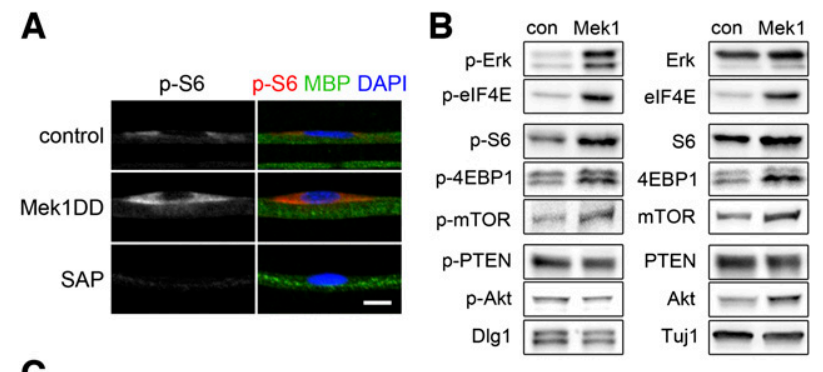

c

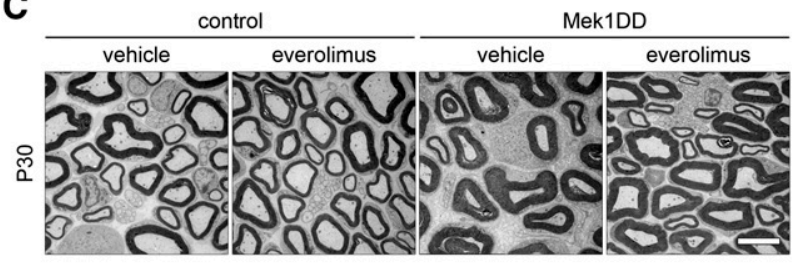

D

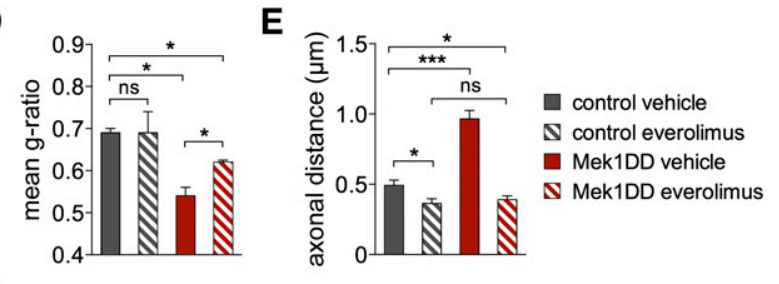

$\mathbf{F}$
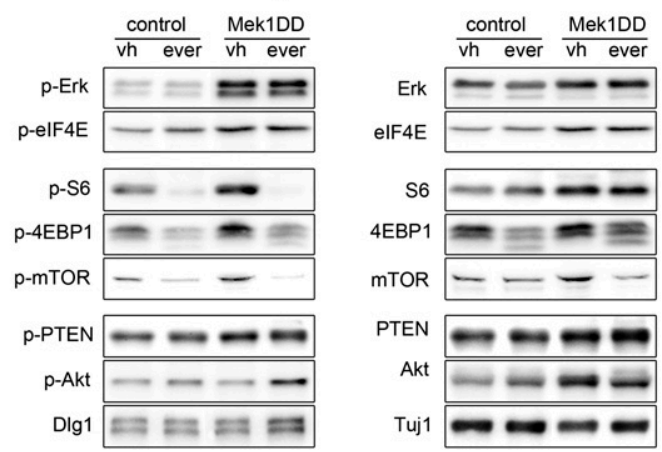

Figure 5. Pharmacological inhibition of $\mathrm{mTORC1}$ rescues axonal packing but not hypermyelination. (A) Staining of P30 teased fibers using antibodies specific for phosphorylated ribosomal protein S6 (p-S6), MBP, and DAPI. The specificity of the antibody directed against p-S6 was verified by treating fibers with shrimp alkaline phosphatase (SAP). (B) Western blot analysis of Erk and eIF4E (top); mTOR and its substrates, S6 and 4EBP1 (middle); PTEN, Dlg1, and their downstream effector, Akt (bottom). (C) Electron microscopy images of P30 sciatic nerves of control and Mek1DD mice treated with the mTORC1 inhibitor everolimus or vehicle. Myelin thickness (g-ratio) $(D)$ and axonal packing $(E)$ in sciatic nerves of control and Mek1DD mice treated with everolimus or vehicle. $(F)$ Western blot analysis indicates that phosphorylation of mTOR and its substrates, S6 and 4EBP1, but not of the Mnk1 substrate eIF4E, is abolished by everolimus treatment. Bars: $A, 10 \mu \mathrm{m} ; C, 5 \mu \mathrm{m}$. Two-tailed paired $t$-test: $\left(^{\star}\right)$ $\left.\left.P<0.05 ;\left.\right|^{\star \star}\right) P<0.01 ;\left.\right|^{\star \star \star}\right) P<0.001$. Error bars indicate $\mathrm{SD}(D)$ and SEM $(E)$.

the mTORC1 substrates S6 and 4EBP1 was strongly reduced (Fig. 5F). As observed in other cell types, everolimus treatment increased p-Akt levels without affecting the Akt regulators Dlg1 and PTEN (Dibble et al. 2009; Julien et al. 2010). In summary, Mek1DD influences the protein translation machinery by mTORC1-independent (eIF4E phosphorylation) and mTORC1-dependent (S6 and 4EBP1 phosphorylation) mechanisms.

Expression of Mek1DD rescues deficits in Schwann cell development and myelination caused by conditional ablation of Shp2 or ErbB3

We previously reported that Shp2 mediates Nrg1/ErbB signaling in Schwann cells (Grossmann et al. 2009). In vivo, Egr2 ${ }^{C r e}$-induced mutation of Shp2 results in pronounced hypomyelination (Fig. 6A,B). We tested whether Mek1DD expression can override the Shp2 dependency in myelination and generated $\mathrm{Egr}^{\mathrm{Cre}} ; \mathrm{Shp} 2^{\mathrm{flf}} ; \mathrm{Mek} 1 \mathrm{DD}$ compound mutant mice. In such mice, Egr2 ${ }^{C r e}$ activated Mek1DD expression and ablated Shp2. Remarkably, Mek1DD expression rescued the hypomyelination seen in $\mathrm{Egr}^{\mathrm{Cre}}$;Shp $2^{f / f}$ mice, resulting at P15 in a g-ratio comparable with that observed in control mice, but myelin growth continued, and axons were hypermyelinated at $\mathrm{P} 90$ (Fig. 6A,B). Analysis of nerve extracts indicated that expression of Mek1DD enhanced p-Erk1/2 but not Dlg1, p-PTEN, and p-Akt in Shp2 mutant Schwann cells (Fig. 6C). We also tested coexpression of a constitutively active variant of PI3K in Shp2 mutant mice, but this did not rescue the hypomyelination seen in Egr2 ${ }^{\mathrm{Cre}} ; \mathrm{Shp} 2^{\mathrm{flf}}$ mice (Fig. 6D,E). Instead, myelination deficits were more pronounced than those observed in Egr2 ${ }^{C r e} ; S h p 2^{f / f}$ animals.

$D h h^{\text {Cre }}$ drives Cre expression in Schwann cell progenitors around E12 and thus introduces recombination earlier than $\mathrm{Egr}^{\mathrm{Cre}}$. Dhh ${ }^{\mathrm{Cre}}$-induced mutation of Shp2 therefore caused more severe phenotypes; i.e., reduced Schwann cell numbers and disrupted entry into the myelination program of remaining Schwann cells (Fig. 6F,G). Expression of Mek1DD in these "early" Shp2 mutants rescued Schwann cell numbers and myelination, but axons were hypermyelinated at P90 (Fig. 6F,G). PI3KDA expression in $D h h^{C r e} ; S h p 2^{f / f}$ mice did not rescue myelination (Supplemental Fig. S6A).

$D h h^{C r e}$-induced mutations of ErbB3 resulted in an almost complete absence of Schwann cells (Fig. 6H). Remarkably, expression of Mek1DD in these ErbB3 mutants rescued Schwann cell development, and Schwann cells were able to myelinate (Fig. $6 \mathrm{H}, \mathrm{I})$. However, at P15 and P90, $36.7 \% \pm 23.7 \%$ and $17.8 \% \pm 0.1 \%$ of axons with diameters $>1 \mu \mathrm{m}$ were nonmyelinated, respectively, compared with $3.5 \% \pm 3.8 \%$ and $0.8 \% \pm 0.0 \%$ in control mice. At P15, the myelin of peripheral axons of rescued $\operatorname{ErbB} 3$ mutants was thinner than in control animals, but axons were hypermyelinated at P90 (Fig. $6 \mathrm{I})$, indicating that myelin growth extended for prolonged periods. We did not observe myelination when PI3KDA was expressed in mice carrying $D h h^{C r e}$-induced mutations in ErbB3 (Supplemental Fig. S6B). We conclude that MAPK activation in Schwann cells compensates for the ablation of ErbB3 or Shp2 and rescues Nrg1-dependent Schwann cell development and myelination.

To assess whether MAPK activation changed the ensheathment fate of axons, we also compared unmyelin- 
Sheean et al.

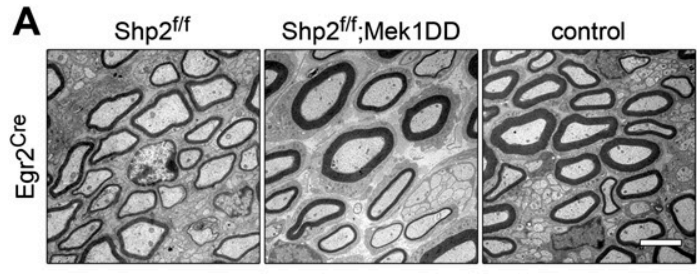

B
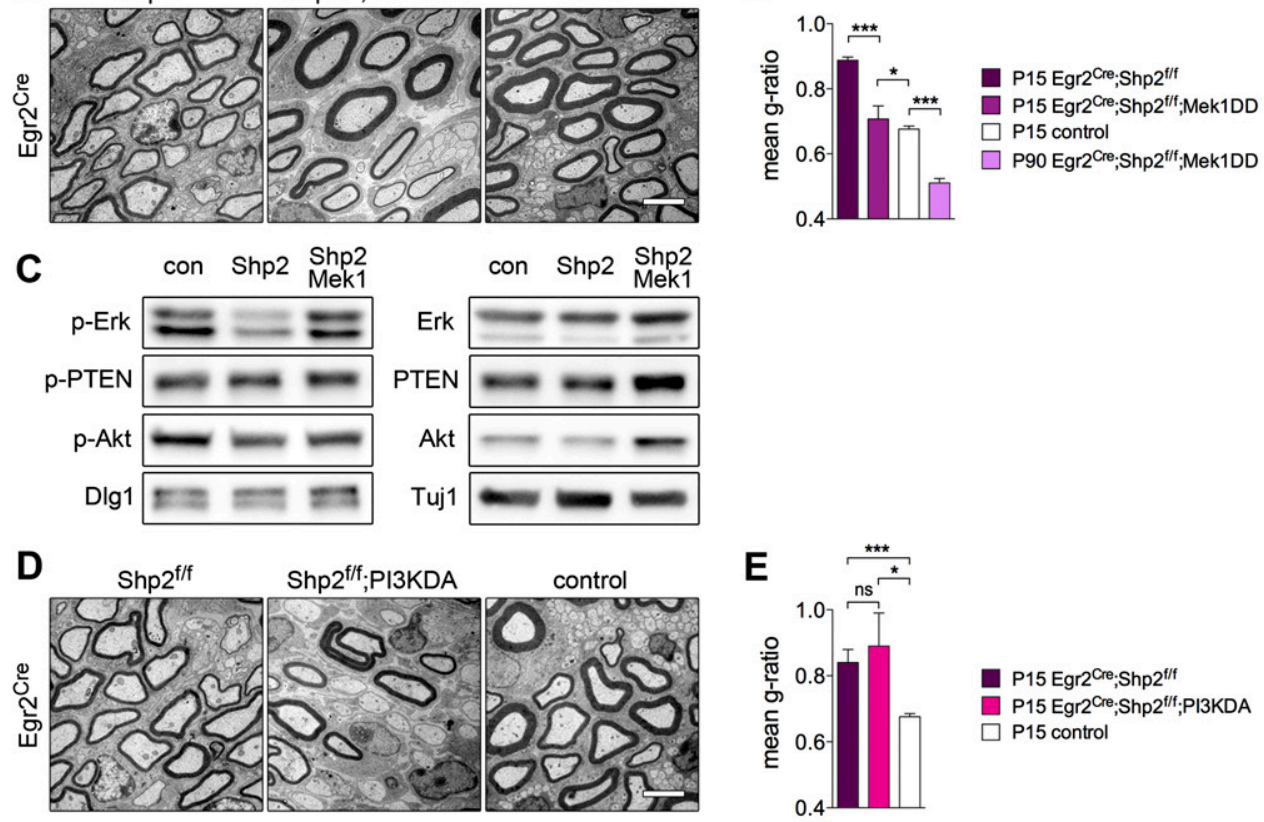

- P15 Egr2 ${ }^{\mathrm{Cre}} ; \mathrm{Shp} 2^{\mathrm{ftf}}$

P15 Egr2 ${ }^{\mathrm{Cre}} ; \mathrm{Shp} 2^{\mathrm{fff} ; \mathrm{PI} 3 \mathrm{KDA}}$

$\square$ P15 control

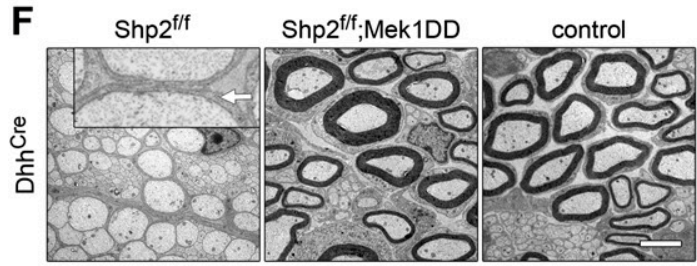

G
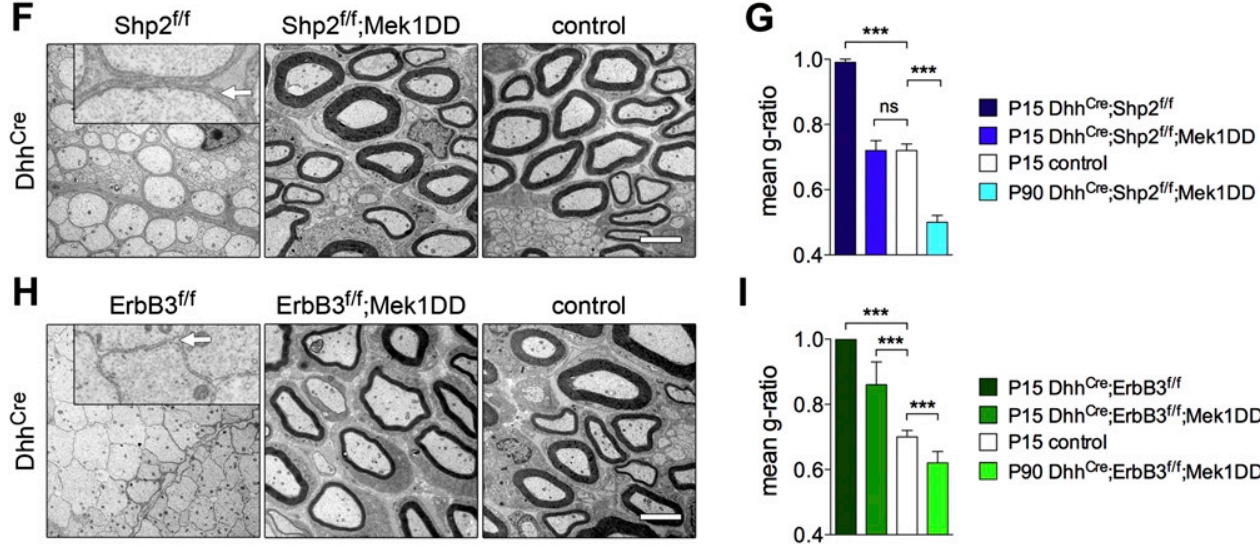

I
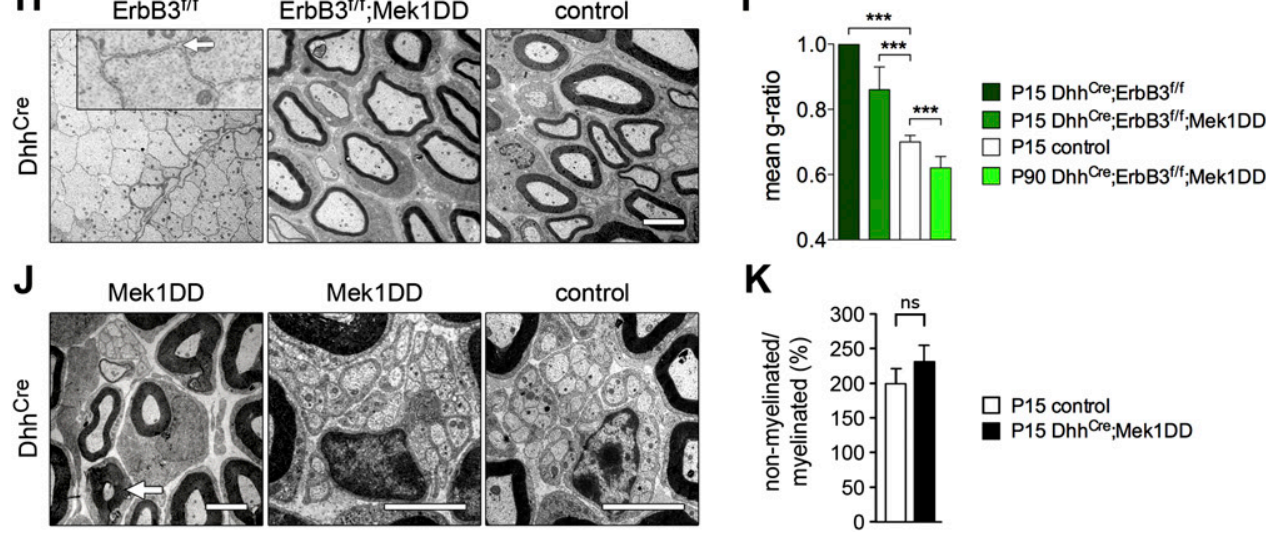

K

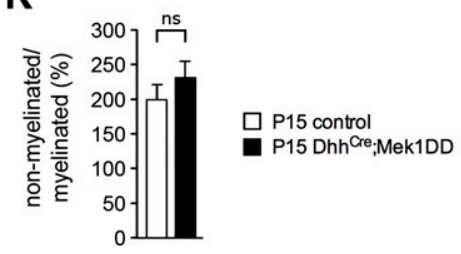

Figure 6. Expression of Mek1DD in Schwann cells compensates for the loss of Shp2 or ErbB3. Electron microscopy analysis at P15 (A) and quantification of myelin thickness (g-ratio) of sciatic nerves (P15 and P90) (B) of Egr2 ${ }^{C r e} ;$ Shp $2^{f / f}$, Egr2 ${ }^{C r e} ; S h p 2^{f / f} ; M e k 1 D D$ and control

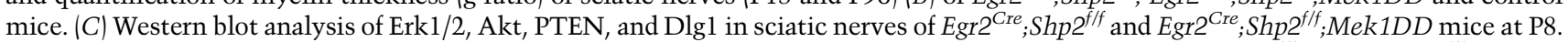
Electron microscopy analysis at $\mathrm{P} 15(D)$ and quantification of myelin g-ratio $(\mathrm{P} 15)(E)$ of sciatic nerves of $E g r 2^{\mathrm{Cre}} ;$ Shp $2^{f / f}$, Egr2 ${ }^{\mathrm{Cre}} ;$;Shp $2^{f / f} ; P I 3 K D A$ and control mice. Electron microscopy analysis at P15 $(F)$ and g-ratio (P15 and P90) $(G)$ of sciatic nerves of $D h h^{C r e} ; S h p 2^{f / f}$, $D h h^{C r e} ;$ Shp $2^{f / f} ; M e k 1 D D$, and control mice; the arrow in the inset points to Schwann cell cytoplasm surrounding an unmyelinated axon. Electron microscopy analysis at P15 $(H)$ and g-ratio (P15 and P90) $(I)$ of sciatic nerves of $D h h^{C r e} ; E r b B 3^{f / f}, D h h^{C r e} ; E r b B 3^{f / f} ; M e k 1 D D$, and control mice; the arrow in the inset points toward axonal membranes not surrounded by Schwann cell cytoplasm. Note that expression of the Mek1DD allele rescues myelination and Schwann cell deficits observed in Shp2 and ErbB3 mutant mice. Electron microscopy analysis $(J)$ and quantification $(K)$ of nonmyelinated/myelinated axons in $D h h^{\mathrm{Cre}}$;Mek1DD and control mice at P15. The arrow in the left panel indicates a myelinated axon with $<1 \mu \mathrm{m}$ axonal diameter in the $D h^{C r e} ; M e k 1 D D$ mutant. The middle and right panels show Remak bundles. Bars, $2 \mu \mathrm{m}$. Two-tailed paired $t$-test: $\left(^{\star}\right) P<0.05 ;\left(^{\star \star}\right) P<0.01 ;\left(^{\star \star \star}\right) P<0.001$. Error bars indicate SEM.

ated axons in $D h h^{C r e}$;Mek1DD and control mice. We rarely observed aberrantly myelinated small axons in the mutants (diameter $<1 \mu \mathrm{m})$. Remak bundles were present and comparable, and the overall ratio of nonmyelinated to myelinated axons was unchanged in $D h h^{\text {Cre }} ;$ Mek $1 D D$ and control mice (Fig. 6J,K). 
Shp2 mutation reduces overall protein synthesis and myelin protein production

We previously reported transcriptional changes in Schwann cells after mutation of Shp2 using Egr2 ${ }^{\text {Cre }}$ (Grossmann et al. 2009). Microarray analysis showed that many genes were deregulated in $\mathrm{Egr}^{\mathrm{Cre}}$;Shp2 $2^{\mathrm{flf}}$ mutant nerves (Supplemental Tables 6-8). Most of these were down-regulated; for instance, 63 genes encoding enzymes of lipid biosynthesis (Supplemental Table 6). Furthermore, qPCR demonstrated that mRNAs of major myelin proteins were down-regulated (Fig. 7A). Thus, the loss of Shp2 affects myelination on a transcriptional level. We examined total protein and myelin protein production in $\mathrm{Egr}^{\mathrm{Cre}}{ }^{\mathrm{S}}$ Shp $2^{\mathrm{f} / \mathrm{f}}$ mutant nerves using pSILAC at P30 and P8. This demonstrated that not only transcription but also overall protein translation and, in particular, production of myelin protein and lipid synthesis enzymes were down-regulated in Shp2 mutant nerves (Fig. 7B,C). To assess this further, we compared changes in mRNA and protein levels (Fig. 7D,E). Analysis of all transcripts indicated a poor correlation between changes in transcript and protein levels at P30 (Pearson's correlation coefficient $r=+0.3$ ). However, when only transcripts that were changed by $>1.2$-fold were included, the correlation improved $(r=+0.44)$. At P8, changes in transcript and protein levels correlated well regardless of whether all transcripts $(r=+0.71)$ or only the subset of transcripts that were changed $(r=+0.75)$ were included in the analysis. Thus, mutation of $\operatorname{Shp} 2$ interferes with myelination on a transcriptional and translational level.

We next tested whether genetic activation of MAPK signaling rescued deficits in protein production and transcript
A
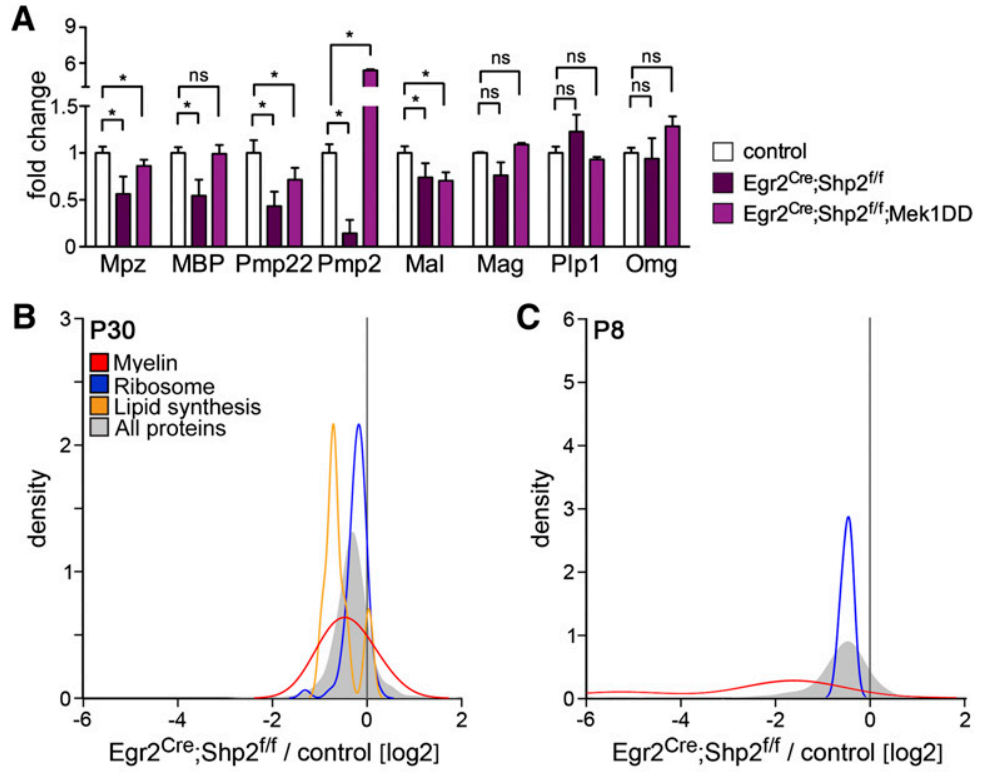

D
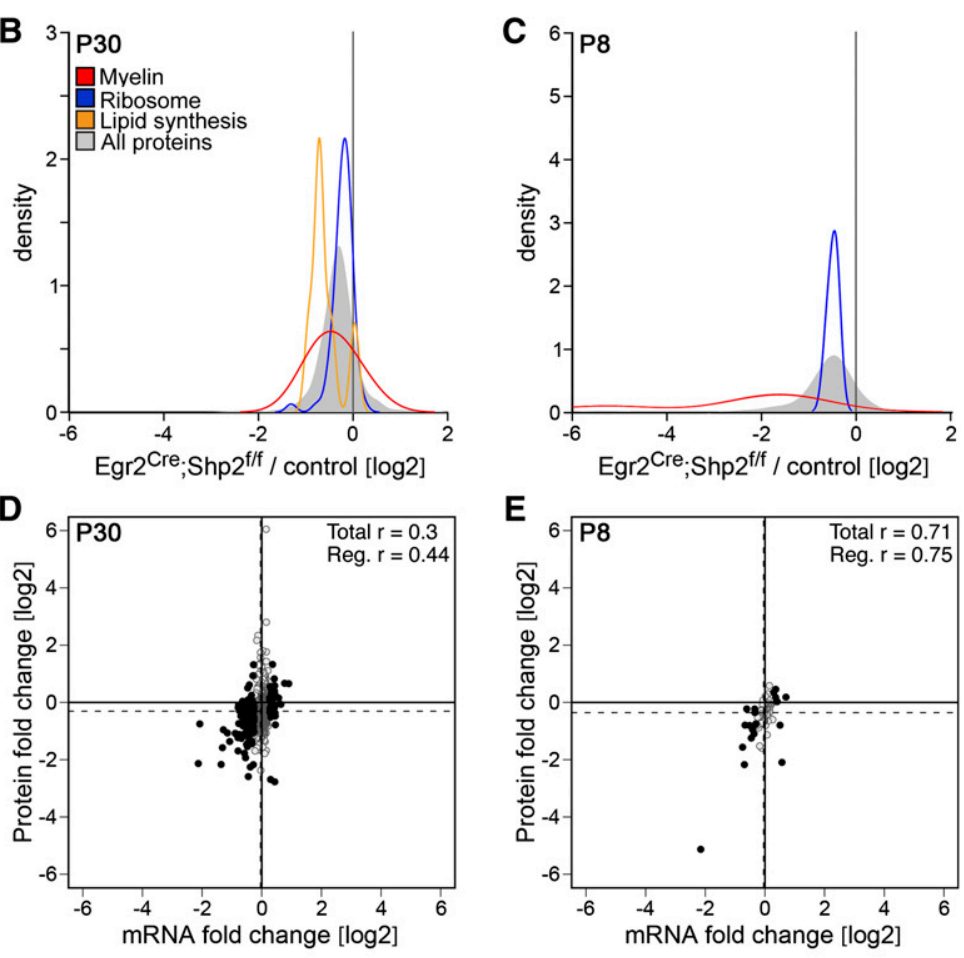

E
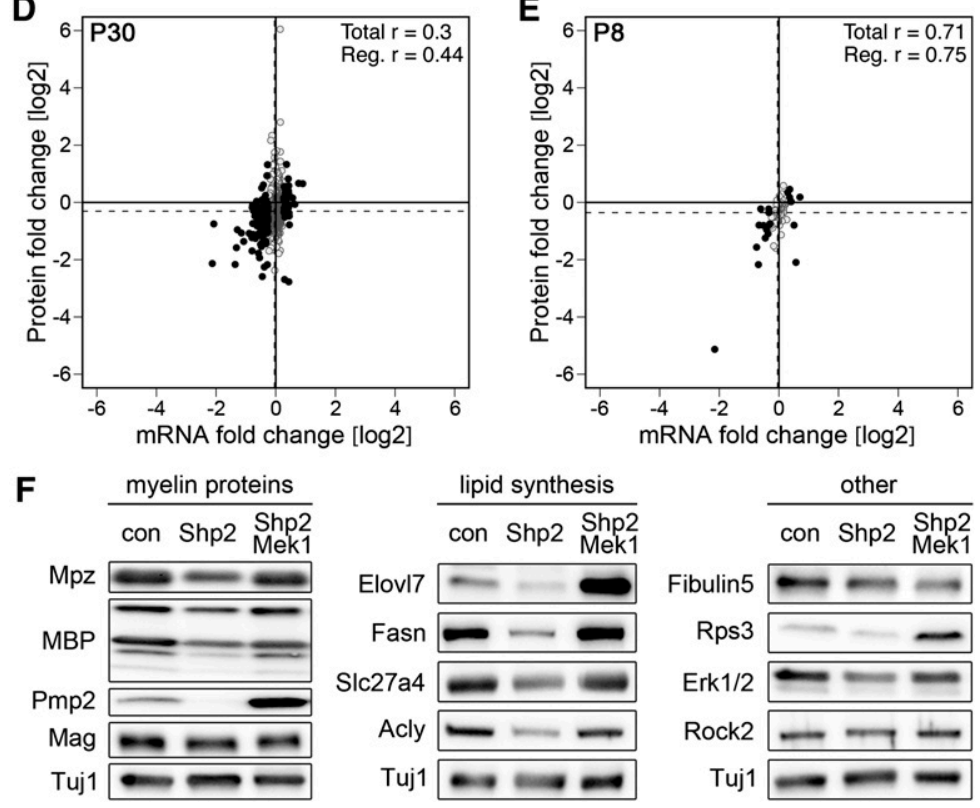

Figure 7. Mek1DD rescues transcriptional and translational deficits of Shp2 mutant Schwann cells. (A) Quantification of transcripts encoding myelin proteins by qPCR at P15. Changes in the levels of several myelin gene transcripts were underestimated in microarray experiments, possibly due to probe saturation. Downregulation of myelin gene mRNA in $\mathrm{Egr}^{\mathrm{Cre}}$;Shp2 $2^{\mathrm{f} / \mathrm{f}}$ mutant nerves was largely rescued by Mek1DD expression. $(B, C)$ Kernel density estimation plots showing the ratios of newly synthesized proteins in the nerves of Egr2 ${ }^{\mathrm{Cre}} ;$ Shp $2^{f / f}$ mutant versus control mice at P30 and P8 as assessed by pSILAC and mass spectrometry; overall proteins and selected protein groups (ribosome, myelin, and enzymes involved in lipid synthesis) are displayed. A shift to the left indicates decreased protein production in $\mathrm{Egr}^{\mathrm{Cre}}$; Shp $2^{\text {f/f }}$ mutants. Enzymes involved in lipid synthesis were not detected when pups were analyzed. $(D, E)$ Correlation plot of fold changes in protein production and mRNA levels in $\mathrm{Egr}^{\mathrm{Cre}}{ }^{\mathrm{CSh}} \mathrm{S}^{\mathrm{flf}}$ mutant versus control nerves at P30 and P8; black dots indicate mRNAs that are changed $>1.2$-fold, and dashed lines indicate the average change in protein/mRNA levels. (F) Western blot analysis of selected proteins identified as down-regulated in the nerves of $\mathrm{Egr}^{\mathrm{Cre}}{ }^{\mathrm{Sh}} \mathrm{Sh} 2^{\mathrm{f} / \mathrm{f}} \mathrm{mu}-$ tants (Shp2) using mass spectrometry. Additional expression of Mek1DD in $\mathrm{Egr2}^{\mathrm{Cre}}$;Shp2 $2^{f / f}$ mutants rescued the levels of these proteins (Shp2/Mek1). Two-tailed paired t-test: $\left(^{\star}\right) P<0.05$. Error bars indicate SD. 
levels caused by the Shp2 mutation using qPCR and Western blot analysis. Many changes that we identified by global mRNA and protein analyses were compensated for (Fig. 7A,F). In particular, down-regulation of myelin proteins Mpz and MBP or lipid biosynthesis factors such as Elov17, Fasn, Slc27a4, and Acly were rescued. Hence, activation of MAPK signaling largely rescues transcriptional as well as translational Schwann cell deficits caused by loss of Shp2.

\section{Discussion}

Here we used newly developed pSILAC methods in mice to demonstrate that synthesis of overall proteins and of myelin proteins massively decreases in Schwann cells during maturation of the peripheral nervous system. However, the termination of myelin growth can be overcome by stimulating protein synthesis through sustained MAPK activation (Mek1DD expression). This results in continuous myelin growth and enhances the efficacy of myelin protein production. It is known that Nrg1/ErbB/ Shp2 signals provide important cues that drive Schwann cell development and myelination. We show here that sustained MAPK activation compensates for the ablation of ErbB3 or Shp2 and thus replaces Nrg1/ErbB signals.

\section{Translational control of myelination}

We used novel pSILAC labeling procedures to record changes in protein production during maturation of the peripheral nervous system in mice. Similar strategies were previously used in cultured cells (Selbach et al. 2008; Doherty et al. 2009). We employed the new strategy to compare protein synthesis and degradation during myelination, but our techniques should also be applicable in other tissue types. In our study, a broad protein repertoire could be quantified. We found that enhanced protein synthesis following activation of MAPK signaling was generally not associated with concordant changes in the expression of the corresponding mRNAs, emphasizing that information about mRNA levels does not suffice to understand the process of myelination.

It was estimated that during myelination, the membrane area of Schwann cells increases several thousandfold, a process accompanied by a huge increase in myelin protein. Our data show that during postnatal development of peripheral myelin, protein production rates are strongly regulated. Translational control of myelination in the peripheral nervous system has received little attention, but it is interesting to note that mutations in components of the initiation factor complex eIF2B result in delayed myelination and aberrant myelin maintenance in the central nervous systems of humans and mice (Leegwater et al. 2001; Geva et al. 2010).

We show that sustained MAPK activation by Mek1DD expression in Schwann cells leads to enhanced protein synthesis and provide evidence that this is mediated by mTORC1-independent mechanisms but in part also by mTORC1-dependent mechanisms. We assessed this by pharmacological inhibition of mTORC1 between P17 and P30; i.e., during a period in which the g-ratio changes little in control mice, although myelin continued to grow in Mek1DD mutants. In Mek1DD mice, myelin growth was slowed down but not fully abrogated by mTORC1 inhibition, but the reduced axonal packing was completely rescued. MAPK signaling phosphorylates the negative regulator of $\mathrm{mTORC} 1(\mathrm{Tsc} 2)$ and can thus increase mTORC1 activity (Ma et al. 2005). Phosphorylation of eIF4E could participate in the MAPK-dependent but mTORC1-independent mechanism regulating myelin growth (Pyronnet et al. 1999). Previous work showed that mTOR mutation retards radial and longitudinal Schwann cell growth (Sherman et al. 2012). Activation of mTOR by PTEN mutation does not result in a general hypermyelination. Instead, a small subpopulation of axons is hypermyelinated, and tomaculi are formed (Goebbels et al. 2012). We also employed here a constitutively active variant of PI3K (PI3KDA) that strongly enhanced Akt activity. Expression of PI3KDA interfered with myelination, indicating that a tight regulation of $\mathrm{PI} 3 \mathrm{~K} / \mathrm{Akt}$ activity is required. In summary, we suggest that the effects of Mek1DD on translation are mediated by mTORC1dependent and mTORC1-independent mechanisms (see Supplemental Fig. S7 for a summary of MAPK signaling and translational control).

\section{Schwann cell dependence on Nrg1/ErbB signals is abrogated by MAPK activation}

Nrg1 and the ErbB2/3 receptors provide pivotal signals for Schwann cell development and myelination that are mediated by the tyrosine phosphatase Shp2 (Grossmann et al. 2009). We found that activation of MAPK signaling by the Mek1DD allele releases Schwann cells from their natural ErbB3/Shp2 dependence. Nrg1/ErbB signals elicit different cellular responses at distinct developmental stages; for example, ErbB3 deficiency during early development results in nerves that are virtually devoid of Schwann cells, a consequence of impaired precursor proliferation and migration (Riethmacher et al. 1997; Lyons et al. 2005). Furthermore, Nrg1/ErbB signaling controls the initiation of Egr2 expression and, consequently, the onset of myelination (Murphy et al. 1996; Lyons et al. 2005; Taveggia et al. 2005). Likewise, mutation of Shp2 or ErbB2 after onset of myelination or heterozygous Nrg1 mutations indicate that $\mathrm{Nrgl} / \mathrm{ErbB}$ signaling controls myelin growth (Garratt et al. 2000; Michailov et al. 2004; Grossmann et al. 2009). Interestingly, activation of MAPK signaling by the Mek $1 D D$ allele largely rescues proliferation, migration, and myelination deficits and thus suffices to replace $\mathrm{Nrg} 1 / \mathrm{ErbB} / \mathrm{Shp} 2$ signals in Schwann cells during early development and myelination.

Previous work indicates that Nrg1/ErbB signaling regulates transcriptional aspects of the myelination program (Lyons et al. 2005; Taveggia et al. 2005). Also, after myelination has commenced, ablation of Shp2 or ErbB2 decreased transcript levels of many myelination genes /Grossmann et al. 2009; this study), and these transcriptional deficits can again be rescued by expression of Mek1DD. Nevertheless, we found that sustained mild activation of MAPK in 
wild-type Schwann cells has little effect on transcription. We therefore propose that saturating levels of MAPK signals in transcriptional and translational control are distinct. The transcriptional myelination program seems fully stimulated by MAPK under normal conditions; i.e., a further increase of MAPK activity does not enhance it significantly. However, when the MAPK signal falls below a threshold, transcription of myelin genes decreases (e.g., Shp2 mutants), and this is again stimulated by increased MAPK activity (e.g., Shp2;Mek1DD mutants). In comparison, translational efficacy is not maximally stimulated by MAPK under normal conditions. Thus, translation responds more dynamically to the strength of MAPK signal: Further MAPK activation enhances translation, whereas reduction of the MAPK signal impairs it. Interestingly, it was noted previously that cellular responses to MAPK activation can depend on the strength and duration of the activating signal (Dikic et al. 1994; Katz et al. 2007).

$\mathrm{Nrg} 1$ and the ErbB2/3 receptors activate many downstream signaling cascades, such as Shp2/MAPK, PI3K/ Akt, PLC/Calcineurin, or Rac1, and extensive work implicated these in various steps of Schwann cell development such as axonal sorting, Schwann cell morphogenesis, and transcriptional control of myelination (Nodari et al. 2007; Grossmann et al. 2009; Kao et al. 2009; Newbern et al. 2011; Goebbels et al. 2012). The fact that the Mek1DD allele can replace Nrg1/ErbB3/Shp2 signaling indicates that many of these signaling cascades are regulated via MAPK, although this might not necessarily be achieved by direct mechanisms.

\section{Myelin thickness and the end of myelination}

Myelin thickness and Schwann cell length (i.e., the internodal distance) are crucial parameters that determine conduction velocity. Furthermore, myelin thickness is highly conserved in evolution and is believed to be optimized for maximal nerve conduction (Huxley and Stampfli 1949; Smith and Koles 1970; Waxman 1980; Wu et al. 2012). However, our analysis shows that one particular myelinated fiber type, D-hair mechanoreceptors, actually conducts faster when hypermyelinated. The conduction velocity of D-hair receptors is therefore not maximized. It is possible that temporal coding of mechanosensory information might be advantageous; for instance, to allow the central nervous system to distinguish stimuli mediated by D-hair and other types of mechanoreceptors.

In mice, peripheral myelination occurs very rapidly during the first postnatal weeks. When myelin reaches its optimal thickness and length, myelin growth slows down but continues at a pace sufficient for myelin maintenance. Cell-autonomous and paracrine mechanisms that end myelination have been discussed in recent studies (Cotter et al. 2010; Macklin 2010). We observed markedly reduced levels of ErbB3, p-Erk1/2, and p-Akt protein and reduced protein synthesis rates during maturation. Since MAPK activation by the Mek1DD allele overcomes the control mechanisms that terminate myelination, activation of MAPK might provide a tool to stimulate myelination and particularly allow Schwann cells to re-enter active myelination in pathological settings.

\section{Materials and methods}

\section{Animals}

ROSA26-STOP-Mek1DD, ROSA26-STOP-PI3KDA, Egr2 ${ }^{\text {Cre }}$, $D h h^{C r e}$, and $S h p 2^{f}$ strains were described (Garratt et al. 2000; Voiculescu et al. 2000; Jaegle et al. 2003; Grossmann et al. 2009; Srinivasan et al. 2009). The ErbB3 ${ }^{f}$ allele is described in the Supplemental Material and in Supplemental Figure S8. Controls in rescue experiments were Cre-negative littermates, and controls in the loss-of-function analyses were Cre-positive and Crenegative Shp2 $2^{f /+}$ and $\mathrm{ErbB}^{f /+}$ littermates.

Control and $\mathrm{Egr}^{\mathrm{Cre}}$;Mek1DD mutant littermates were injected intraperitoneally between P17 and P30 $5 \mathrm{~d}$ a week for $2 \mathrm{wk}$ with everolimus (5 mg/kg body weight; Sigma) dissolved in DMSO/PBS (5/95 [v/v]) or corresponding vehicle. Nerves from everolimus-treated mice were isolated within $2 \mathrm{~h}$ after the last treatment.

\section{Immunohistology and g-ratio analysis}

Immunohistology and electron microscopy were performed as described (Grossmann et al. 2009; Wende et al. 2012). Mean g-ratios were calculated with a correction including nonmyelinated axons $>1 \mu \mathrm{m}$ diameter. The standard deviation between values in individual animals was taken as error (see the Supplemental Material).

\section{Microarray and $q P C R$ analysis}

Total RNA from sciatic nerves was labeled and hybridized to Affymetrix Mouse Genechip 1.0 or 2.0 ST arrays as specified by the manufacturer. Microarray data were analyzed using Partek Genomics suite 6.5 and 6.6. For the comparison of mRNA levels in sciatic nerves, we used wild-type mice aged P11 or P33, the midpoints of the pSILAC experiments. We supplemented each P11 or P33 sample with equal amounts of ERCC RNA Spike-in Control Mix1 (Ambion), which was further used for normalization of microarray data to obtain expression levels per nerve (Loven et al. 2012). For qPCR analysis, cDNA was synthetized using SuperScript III (Invitrogen) and analyzed using Absolute qPCR SYBR Green mix (AbGene) on a Bio-Rad C1000 Thermal Cycler (see the Supplemental Material). For the comparison of mRNA levels in sciatic nerves of P0, P8, P15, P30, and P62 wild-type mice, we used additional spike-in of Caenorhabditis elegans RNA for normalization (see the Supplemental Material).

In vivo pSILAC labeling and mass spectrometry

Custom-made chow containing Lys4 or Lys8 $\left(\mathrm{D}_{4}\right.$-L-lysine and ${ }^{13} \mathrm{C}_{4},{ }^{15} \mathrm{~N}_{4}$-L-lysine; Silantes no. 230914520 and 230984640) was used to pulse-label P30 animals. P8 mice cannot be labeled with solid food; they were therefore labeled via mother's milk provided by completely Lys6-labeled $\left({ }^{13} \mathrm{C}_{6}\right.$-lysine; Silantes no. 230924530) foster mothers (Krüger et al. 2008). Sciatic nerves were isolated and analyzed by mass spectrometry using a $\mathrm{Q}$ Exactive mass spectrometer (Thermo Scientific). For analysis, non-normalized MaxQuant ratios were used, and proteins with at least three ratio counts were included (see the Supplemental Material). 


\section{Acknowledgments}

We are deeply grateful to Mandy Terne for her expert technical support. We also thank Bettina Brandt and Carola Griffel for performing electron microscopic analyses. We thank Petra Stallerow and Claudia Päseler for the animal husbandry, as well as Sebastian Memczak, Oliver Schlüter, and Yanling Liu for a generous gift of C. elegans RNA and Dlg1 antibody, respectively. We also thank Norbert Hübner and Gabriele Born for performing the microarray hybridization and scanning. Finally, we thank Dominique Bröhl and Michael Strehle for critical reading of the manuscript. This work was supported by SFB665 (projects B1 and B6) from the Deutsche Forschungsgemeinschaft to C.B., T.M., A.N.G., and G.R.L., respectively. M.E.S. designed, performed, or supervised the majority of the histochemical, biochemical, and molecular biology experiments and their analyses; supervised mouse breeding; analyzed electron microscopy and microarray data; and participated in the design and analysis of pSILAC data and in the writing of the study and figure design. E.M. processed samples for mass spectrometry experiments, performed and participated in the design of the experiments, designed and performed the analysis of the data, designed figures showing pSILAC analyses and pSILAC/microarray correlations, and wrote the corresponding Materials and Methods section. C.C. designed myelination analysis files, performed qPCR and microarray analyses, supervised the revision process, and participated in writing of the study and figure design.

\section{References}

Cotter L, Ozçelik M, Jacob C, Pereira JA, Locher V, Baumann R, Relvas JB, Suter U, Tricaud N. 2010. Dlg1-PTEN interaction regulates myelin thickness to prevent damaging peripheral nerve overmyelination. Science 328: 1415-1418.

Court Fa, Sherman DL, Pratt T, Garry EM, Ribchester RR, Cottrell DF, Fleetwood-Walker SM, Brophy PJ. 2004. Restricted growth of Schwann cells lacking Cajal bands slows conduction in myelinated nerves. Nature 431: 191-195.

Cox J, Mann M. 2011. Quantitative, high-resolution proteomics for data-driven systems biology. Annu Rev Biochem 80: 273299.

Dibble CC, Asara JM, Manning BD. 2009. Characterization of Rictor phosphorylation sites reveals direct regulation of mTOR complex 2 by S6K1. Mol Cell Biol 29: 5657-5670.

Dikic I, Schlessinger J, Lax I. 1994. PC12 cells overexpressing the insulin receptor undergo insulin-dependent neuronal differentiation. Curr Biol 4: 702-708.

Doherty MK, Hammond DE, Clague MJ, Gaskell SJ, Beynon RJ. 2009. Turnover of the human proteome: Determination of protein intracellular stability by dynamic SILAC. J Proteome Res 8: 104-112.

Donaldson HH, Hoke GW. 1905. On the areas of the axis cylinder and medullary sheath as seen in cross sections of the spinal nerves of vertebrates. J Comp Neurol Psychol 15: 1-16.

Dowling RJ, Topisirovic I, Fonseca BD, Sonenberg N. 2010.Dissecting the role of mTOR: Lessons from mTOR inhibitors. Biochim Biophys Acta 1804: 433-439.

Fricker FR, Antunes-Martins A, Galino J, Paramsothy R, La Russa F, Perkins J, Goldberg R, Brelstaff J, Zhu N, McMahon S, et al. 2013. Axonal Neuregulin-1 is a rate limiting but not essential factor for nerve remyelination. Brain 136: $2279-2297$.

Garratt AN, Voiculescu O, Topilko P, Charnay P, Birchmeier C. 2000. A dual role of erbB2 in myelination and in expansion of the Schwann cell precursor pool. J Cell Biol 148: 1035-1046.
Geva M, Cabilly Y, Assaf Y, Mindroul N, Marom L, Raini G, Pinchasi D, Elroy-Stein O. 2010. A mouse model for eukaryotic translation initiation factor 2B-leucodystrophy reveals abnormal development of brain white matter. Brain 133: 2448-2461.

Goebbels S, Oltrogge JH, Wolfer S, Wieser GL, Nientiedt T, Pieper A, Ruhwedel T, Groszer M, Sereda MW, Nave KA. 2012. Genetic disruption of Pten in a novel mouse model of tomaculous neuropathy. EMBO Molecular Medicine 4: 486499.

Grossmann KS, Wende H, Paul FE, Cheret C, Garratt AN, Zurborg S, Feinberg K, Besser D, Schulz H, Peles E, et al. 2009. The tyrosine phosphatase Shp2 (PTPN11) directs Neuregulin-1/ErbB signaling throughout Schwann cell development. Proc Natl Acad Sci 106: 16704-16709.

Hay N, Sonenberg N. 2004. Upstream and downstream of mTOR. Genes Dev 18: 1926-1945.

Huxley AF, Stampfli R. 1949. Evidence for saltatory conduction in peripheral myelinated nerve fibres. J Physiol 108: 315-339.

Ishii A, Furusho M, Bansal R. 2013. Sustained activation of ERK1/2 MAPK in oligodendrocytes and schwann cells enhances myelin growth and stimulates oligodendrocyte progenitor expansion. J Neurosci 33: 175-186.

Jaegle M, Ghazvini M, Mandemakers W, Piirsoo M, Driegen S, Levavasseur F, Raghoenath S, Grosveld F, Meijer D. 2003. The POU proteins Brn-2 and Oct- 6 share important functions in Schwann cell development. Genes Dev 17: 13801391.

Julien LA, Carriere A, Moreau J, Roux PP. 2010. mTORC1activated S6K1 phosphorylates Rictor on threonine 1135 and regulates mTORC2 signaling. Mol Cell Biol 30: 908-921.

Kao SC, Wu H, Xie J, Chang CP, Ranish JA, Graef IA, Crabtree GR. 2009. Calcineurin/NFAT signaling is required for neuregulin-regulated Schwann cell differentiation. Science 323: 651-654.

Katz M, Amit I, Yarden Y. 2007. Regulation of MAPKs by growth factors and receptor tyrosine kinases. Biochim Biophys Acta 1773: 1161-1176.

Kelleher RJ, Govindarajan A, Jung H-Y, Kang H, Tonegawa S. 2004. Translational control by MAPK signaling in long-term synaptic plasticity and memory. Cell 116: 467-479.

Kong J, Lasko P. 2012. Translational control in cellular and developmental processes. Nat Rev Genet 13: 383-394.

Krüger M, Moser M, Ussar S, Thievessen I, Luber CA, Forner F, Schmidt S, Zanivan S, Fässler R, Mann M. 2008. SILAC mouse for quantitative proteomics uncovers kindlin-3 as an essential factor for red blood cell function. Cell 134: 353-364.

Leegwater PA, Vermeulen G, Konst AA, Naidu S, Mulders J, Visser A, Kersbergen P, Mobach D, Fonds D, van Berkel CG, et al. 2001. Subunits of the translation initiation factor eIF2B are mutant in leukoencephalopathy with vanishing white matter. Nat Genet 29: 383-388.

Loven J, Orlando DA, Sigova AA, Lin CY, Rahl PB, Burge CB, Levens DL, Lee TI, Young RA. 2012. Revisiting global gene expression analysis. Cell 151: 476-482.

Lyons DA, Pogoda H-M, Voas MG, Woods IG, Diamond B, Nix R, Arana N, Jacobs J, Talbot WS. 2005. erbb3 and erbb2 are essential for Schwann cell migration and myelination in zebrafish. Curr Biol 15: 513-524.

Ma L, Chen Z, Erdjument-Bromage H, Tempst P, Pandolfi PP. 2005. Phosphorylation and functional inactivation of TSC2 by Erk implications for tuberous sclerosis and cancer pathogenesis. Cell 121: 179-193.

Macklin WB. 2010. The myelin brake: When enough is enough. Sci Signal 3: pe32. 
Michailov GV, Sereda MW, Brinkmann BG, Fischer TM, Haug B, Birchmeier C, Role L, Lai C, Schwab MH, Nave K-A. 2004. Axonal neuregulin-1 regulates myelin sheath thickness. Science 304: 700-703.

Milenkovic N, Wetzel C, Moshourab R, Lewin GR. 2008. Speed and temperature dependences of mechanotransduction in afferent fibers recorded from the mouse saphenous nerve. J Neurophysiol 100: 2771-2783.

Monk KR, Oshima K, Jors S, Heller S, Talbot WS. 2011. Gpr126 is essential for peripheral nerve development and myelination in mammals. Development 138: 2673-2680.

Murphy P, Topilko P, Schneider-Maunoury S, Seitanidou T, Baron-Van Evercooren A, Charnay P. 1996. The regulation of Krox-20 expression reveals important steps in the control of peripheral glial cell development. Development 122: 2847-2857.

Narayanan SP, Flores AI, Wang F, Macklin WB. 2009. Akt signals through the mammalian target of rapamycin pathway to regulate CNS myelination. I Neurosci 29: 6860-6870.

Newbern J, Birchmeier C. 2010. Nrg1/ErbB signaling networks in Schwann cell development and myelination. Semin Cell Dev Biol 21: 922-928.

Newbern JM, Li X, Shoemaker SE, Zhou J, Zhong J, Wu Y, Bonder D, Hollenback S, Coppola G, Geschwind DH, et al. 2011. Specific functions for ERK/MAPK signaling during PNS development. Neuron 69: 91-105.

Nodari A, Zambroni D, Quattrini A, Court FA, D'Urso A, Recchia A, Tybulewicz VL, Wrabetz L, Feltri ML. 2007. $\beta 1$ integrin activates Rac1 in Schwann cells to generate radial lamellae during axonal sorting and myelination. I Cell Biol 177: 1063-1075.

Pyronnet S, Imataka H, Gingras AC, Fukunaga R, Hunter T, Sonenberg N. 1999. Human eukaryotic translation initiation factor 4G (eIF4G) recruits mnk1 to phosphorylate eIF4E. EMBO J 18: 270-279.

Quarles RH, Macklin WB, Morell P. 2006. Myelin formation, structure and biochemistry. In Basic neurochemistry: Molecular, cellular and medical aspects, 7th edition (ed. Siegel G, et al.), pp. 51-72. Elsevier, MA.

Riethmacher D, Sonnenberg-Riethmacher E, Brinkmann V, Yamaai T, Lewin GR, Birchmeier C. 1997. Severe neuropathies in mice with targeted mutations in the ErbB3 receptor. Nature 389: 725-730.

Roux PP, Shahbazian D, Vu H, Holz MK, Cohen MS, Taunton J, Sonenberg N, Blenis J. 2007. RAS/ERK signaling promotes site-specific ribosomal protein S6 phosphorylation via RSK and stimulates cap-dependent translation. J Biol Chem 282: 14056-14064.

Schuurman HJ, Cottens S, Fuchs S, Joergensen J, Meerloo T, Sedrani R, Tanner M, Zenke G, Schuler W. 1997. SDZ RAD, a new rapamycin derivative: Synergism with cyclosporine. Transplantation 64: 32-35.

Schwanhäusser B, Busse D, Li N, Dittmar G, Schuchhardt J, Wolf J, Chen W, Selbach M. 2011. Global quantification of mammalian gene expression control. Nature 473: 337-342.

Selbach M, Schwanhäusser B, Thierfelder N, Fang Z, Khanin R, Rajewsky N. 2008. Widespread changes in protein synthesis induced by microRNAs. Nature 455: 58-63.

Sherman DL, Krols M, Wu L-MN, Grove M, Nave K-A, Gangloff Y-G, Brophy PJ. 2012. Arrest of myelination and reduced axon growth when Schwann cells lack mTOR. J Neurosci 32: 1817-1825.

Smith RS, Koles ZJ. 1970. Myelinated nerve fibers: Computed effect of myelin thickness on conduction velocity. Am I Physiol 219: 1256-1258.
Song MS, Salmena L, Pandolfi PP. 2012. The functions and regulation of the PTEN tumour suppressor. Natl Rev 13: 283-296.

Srinivasan L, Sasaki Y, Calado DP, Zhang B, Paik JH, DePinho RA, Kutok JL, Kearney JF, Otipoby KL, Rajewsky K. 2009. PI3 kinase signals BCR-dependent mature B cell survival. Cell 139: $573-586$.

Suter U, Scherer SS. 2003. Disease mechanisms in inherited neuropathies. Nat Rev Neurosci 4: 714-726.

Svaren J, Meijer D. 2008. The molecular machinery of myelin gene transcription in Schwann cells. Glia 56: 1541-1551.

Taveggia C, Zanazzi G, Petrylak A, Yano H, Rosenbluth J, Einheber S, Xu X, Esper RM, Loeb JA, Shrager P, et al. 2005. Neuregulin-1 type III determines the ensheathment fate of axons. Neuron 47: 681-694.

Topisirovic I, Sonenberg N. 2011. mRNA translation and energy metabolism in cancer: The role of the MAPK and mTORC1 pathways. Cold Spring Harb Symp Quant Biol 76: 355-367.

Voiculescu O, Charnay P, Schneider-Maunoury S. 2000. Expression pattern of a Krox-20/Cre knock-in allele in the developing hindbrain, bones, and peripheral nervous system. Genesis 26: 123-126.

Waskiewicz AJ, Flynn A, Proud CG, Cooper JA. 1997. Mitogenactivated protein kinases activate the serine/threonine kinases Mnk1 and Mnk2. EMBO J 16: 1909-1920.

Waxman SG. 1980. Determinants of conduction velocity in myelinated nerve fibers. Muscle Nerve 3: 141-150.

Wende H, Lechner SG, Cheret C, Bourane S, Kolanczyk ME, Pattyn A, Reuter K, Munier FL, Carroll P, Lewin GR, et al. 2012. The transcription factor c-Maf controls touch receptor development and function. Science 335: 1373-1376.

Wu LMN, Williams A, Delaney A, Sherman DL, Brophy PJ. 2012. Increasing internodal distance in myelinated nerves accelerates nerve conduction to a flat maximum. Curr Biol 22: 1957-1961. 


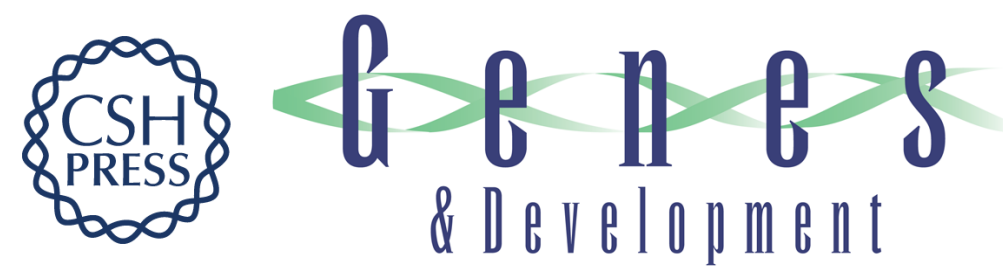

\section{Activation of MAPK overrides the termination of myelin growth and replaces Nrg1/ErbB3 signals during Schwann cell development and myelination}

Maria E. Sheean, Erik McShane, Cyril Cheret, et al.

Genes Dev. 2014, 28:

Access the most recent version at doi:10.1101/gad.230045.113

Supplemental Material

References

Creative Commons License

Email Alerting Service
http://genesdev.cshlp.org/content/suppl/2014/01/31/28.3.290.DC1

This article cites 55 articles, 21 of which can be accessed free at: http://genesdev.cshlp.org/content/28/3/290.full.html\#ref-list-1

This article, published in Genes \& Development, is available under a Creative Commons License (Attribution-NonCommercial 3.0 Unported), as described at http://creativecommons.org/licenses/by-nc/3.0/.

Receive free email alerts when new articles cite this article - sign up in the box at the top right corner of the article or click here.

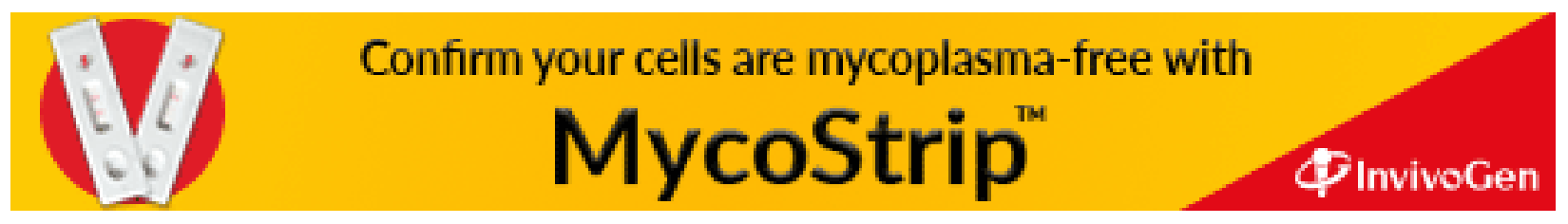

